\title{
Spatial distribution and interannual variability of coastal fog and low clouds cover in the hyperarid Atacama Desert and implications for past and present Tillandsia landbeckii ecosystems
}

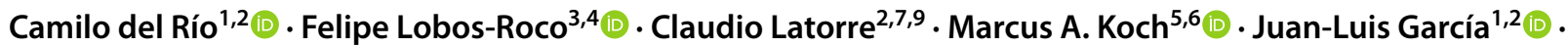 \\ Pablo Osses $^{1,2} \cdot$ Fabrice Lambert $^{1,11} \cdot$ Fernando Alfaro $^{8,9} \cdot$ Alexander Siegmund $^{6,10}$ (i)
}

Received: 11 March 2021 / Accepted: 8 August 2021 / Published online: 15 September 2021

(C) The Author(s) 2021

\begin{abstract}
The hyperarid Atacama Desert coast receives scarce moisture inputs mainly from the Pacific Ocean in the form of marine advective fog. The collected moisture supports highly specialized ecosystems, where the bromeliad Tillandsia landbeckii is the dominant species. The fog and low clouds (FLCs) on which these ecosystems depend are affected in their interannual variability and spatial distribution by global phenomena, such as ENSO. Yet, there is a lack of understanding of how ENSO influences recent FLCs spatial changes and their interconnections and how these variations can affect existing Tillandsia stands. In this study, we analyze FLCs occurrence, its trends and the influence of ENSO on the interannual variations of FLCs presence by processing GOES satellite images (1995-2017). Our results show that ENSO exerts a significant influence over FLCs interannual variability in the Atacama at $20^{\circ} \mathrm{S}$. Linear regression analyses reveal a relation between ENSO3.4 anomalies and FLCs with opposite seasonal effects depending on the ENSO phase. During summer (winter), the ENSO warm phase is associated with an increase (decrease) of the FLCs occurrence, whereas the opposite occurs during ENSO cool phases. In addition, the ONI Index explains up to $\sim 50$ and $\sim 60 \%$ variance of the interannual FLCs presence in the T. landbeckii site during summer and winter, respectively. Finally, weak negative (positive) trends of FLCs presence are observed above (below) $1000 \mathrm{~m}$ a. s. 1. These results have direct implications for understanding the present and past distribution of Tillandsia ecosystems under the extreme conditions characterizing our study area.
\end{abstract}

Keywords Chile $\cdot$ ENSO $\cdot$ Fog ecosystems $\cdot$ GOES $\cdot$ Interdecadal Pacific Oscillation $\cdot$ Southeast Pacific Ocean

Handling editor: Marcus Koch.

Contribution to "Living at its dry limits - Tillandsiales in the Atacama Desert".

Camilo del Río

cdelriol@uc.cl

1 Instituto de Geografía, Pontificia Universidad Católica de Chile, Santiago, Chile

2 Centro UC Desierto de Atacama, Santiago, Chile

3 Departamento de Ingeniería Hidráulica Y Ambiental, Pontificia Universidad Católica de Chile, Santiago, Chile

4 Meteorology and Air Quality Group, Wageningen University, Wageningen, The Netherlands

5 Centre for Organismal Studies, Heidelberg University, 69120 Heidelberg, Germany

6 Heidelberg Center for the Environment HCE, Heidelberg University, 69120 Heidelberg, Germany
7 Departamento de Ecología, Pontificia Universidad Católica de Chile, Santiago, Chile

8 GEMA Center for Genomics, Ecology and Environment, Universidad Mayor, Camino La Piramide 5750, Huechuraba, Santiago, Chile

9 Instituto de Ecología \& Biodiversidad (IEB), Casilla 653, Santiago, Chile

10 Research Group for Earth Observation (rgeo), Department of Geography, Heidelberg University of Education, Heidelberg, Germany

11 Center for Climate and Resilience Research, Santiago, Chile 


\section{Introduction}

The Atacama Desert, located along the western margin of the Andes Cordillera from southern Perú to northern Chile, is one of the oldest and driest places on Earth (Hartley et al. 2005; Clarke 2006). Its hyper-aridity has supposedly existed for at least 10 million years (Jordan et al. 2014; Armijo et al. 2015). However, the evidence of the variations of such an extreme climate is present at multiple timescales in the Andes and the Atacama central depression, where phases of increased moisture or anomalous precipitation events have been observed during the Pliocene (Amundson et al. 2012), Pleistocene, and Holocene (Gayo et al. 2012; Latorre et al. 2013; Santoro et al. 2017; McRostie et al. 2017; Pfeiffer et al. 2018).

Along the Atacama coast, climate variations have been associated not only with the infrequent rainfalls (Ortlieb, 1995; Houston 2006) but also with changes in the moisture inputs coming from the Pacific Ocean and, more specifically, with fluctuations of water inputs from marine advective fog (Latorre et al. 2011).

Fog and low clouds (FLCs) in the coastal Atacama are a consequence of complex oceanic-atmospheric interactions and the existence of high and pronounced coastal ridges that intersects the moist marine boundary layer. On the one hand, here we find cold coastal sea surface temperatures (SSTs) resulting from the northward-flowing Humboldt current and the upwelling of cold, nutrient-rich water masses (Thiel et al. 2007). On the other hand, the large-scale subsidence of warm and dry air masses typical of subtropical regions determines the formation of the Southeast Pacific Anticyclone (SEPA). This phenomenon triggers the formation of a strong thermal inversion layer (TIL) and therefore promotes the presence of a spatial-spread low-clouds deck within the marine boundary layer (MBL) (Serpetzoglou et al. 2008; Garreaud et al. 2011; Wood et al. 2011). When this extensive Stratocumulus cloud (Sc-cloud) deck intersects the Atacama Coastal Cordillera, it produces a highly dynamic advective marine fog (See Fig. 1a and 1b) (Cereceda et al. 2002; Garreaud et al. 2008; Muñoz et al. 2016; Lobos et al. 2018; del Río et al. 2018; 2021). Thus, the occurrence of FLCs in the study area results from the interactions between large-scale and local factors, such as the land-sea heat fluxes. Variations of air subsidence intensity and coastal SSTs are the main factors that determine the formation of the MBL and the strength of the TIL. Therefore, their variations in time and space define both the seasonal cycles and the synoptic and interannual variability of the FLCs frequency (Garreaud et al. 2007).

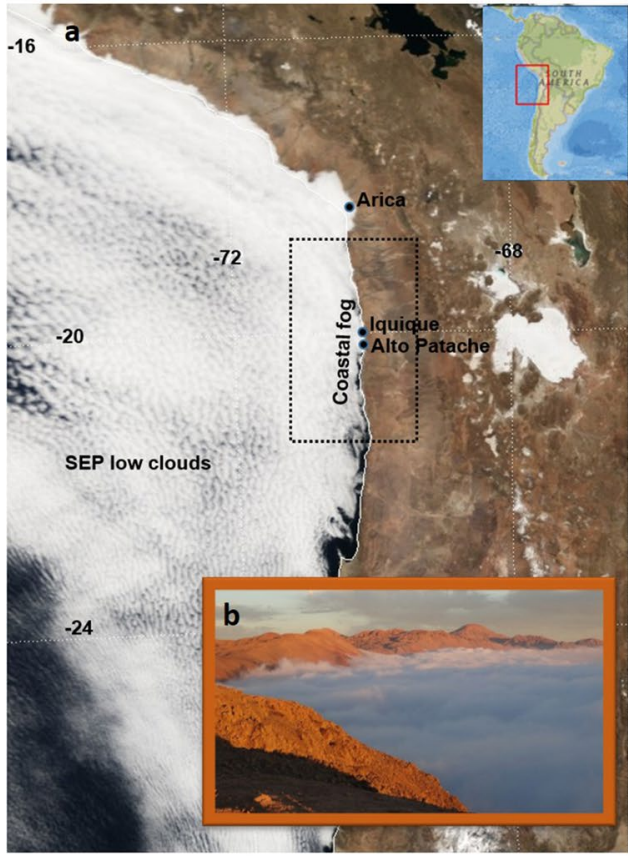

Fig. 1 The geographical context of the study area. a Low clouds over the south-east Pacific (SEP) along the coastal Atacama Desert (MODIS image 01-09-2017). The black dotted rectangle corresponds to the area analyzed by the GOES satellite; $\mathbf{b}$ advective fog intersecting the pronounced Coastal Cordillera at Alto Patache; $\mathbf{c}$ distribution of Tillandsia landbeckii patches (in green) along the Coastal Cordil-

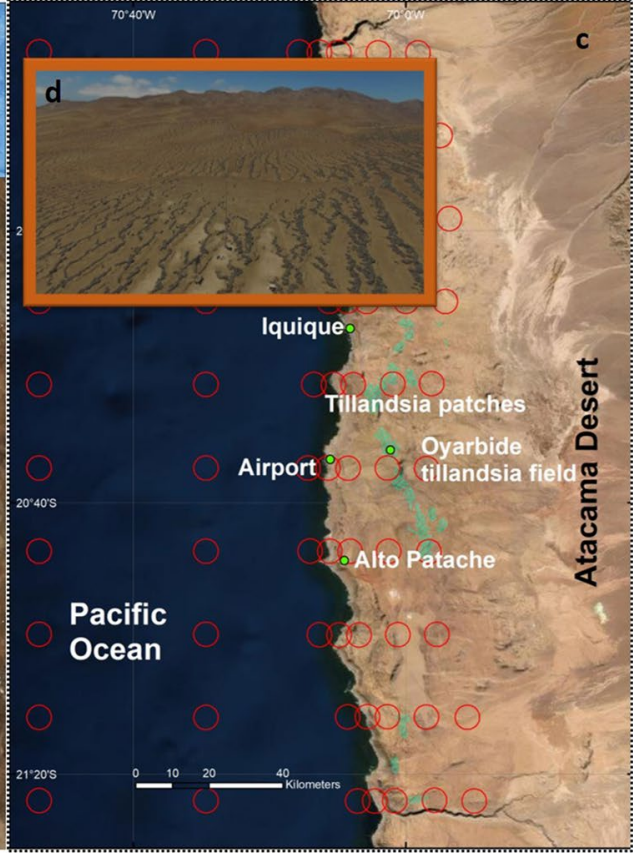

lera. This representation is based on a Google Earth interpretation. The red circles represent the sampling areas used to characterize the distribution and variability of fog and low clouds. Longitudinally, they are located at $65,20,5 \mathrm{~km}$ offshore, over the coastline, and at 5,15 and $25 \mathrm{~km}$ inland; latitudinally every $21 \mathrm{~km}$; $\mathbf{d}$ typical "banded distribution" of Tillandsia landbeckii ecosystems at Cerro Oyarbide 
Over the last decade, various authors have analyzed the recent climatology and trends of the FLCs presence along the coast of northern Chile (Garreaud et al. 2008; Muñoz et al. 2011; 2016; Schulz et al. 2011a; 2011b; Seethala et al. 2015; del Río et al. 2018). For instance, Muñoz et al. (2016), using observations taken at airports located along the northern Chilean coast, suggested that there have been no changes in low cloud cover during summers over the last 30 years. However, this same dataset revealed a slight increase in low clouds cover in winter and early spring. These trends are consistent with the results of Seethala et al. (2015), who showed an increase in the annual average low clouds presence trend in the southeast Pacific for the period 1984-2009. However, these observations do not necessarily indicate the presence of fog or its interaction with the surface but rather correspond to Sc clouds presence over the Southeast Pacific Ocean and the coastal plain. This uncertainty makes it difficult to fully understand fog climates' temporal and spatial variations occurring on the Coastal Cordillera.

At the synoptic scale, the potentially significant influence of El Niño Southern Oscillation (ENSO) and the Interdecadal Pacific Oscillation (IPO) on FLCs interannual and decadal variabilities has been barely discussed. For the interannual timescales, del Río et al. (2018) showed higher fog presence and fog water yields during summer for strong-toextreme El Niño years in the tropical and hyper-arid coastal northern Chile $\left(\sim 20^{\circ} \mathrm{S}\right)$. The opposite has been observed more south, in the semiarid region $\left(\sim 30^{\circ} \mathrm{S}\right)$, where higher fog presence occurs during spring in La Niña years (Garreaud et al. 2008). For the interdecadal timescales, an intensification of La Niña years has occurred over the last decades (during the current negative IPO phase) (Meehl et al. 2021; Sohn et al. 2013). This phenomenon has resulted in cooler sea-surface and air temperatures within the MBL and the intensification of the SEPA (Schulz et al. 2011a; Muñoz et al. 2016). These circumstances led to atmospheric stability and conditions which are presumably favorable to fog formation. Increased air subsidence is also related to the negative IPO and the consequent SEPA intensification. In addition, Schulz et al. (2011a) observations, based on radiosonde measurements, show a TIL altitude weak negative trend of the order of $90 \mathrm{~m}$ between 1960 and 2009 in Antofagasta. Also, the study of Muñoz et al. (2016) shows similar trends for the last three decades, together with a cloud base altitude decrease of the order of $100 \mathrm{~m}$ per decade. In recent decades, variations of the inversion base height and the cloud thickness have likely changed the FLCs distribution. While some regions may now lie above the typical fog range, other regions may be characterized by increasing FLCs occurrence. Thus, a space-time climate analysis of the FLCs phenomenon is relevant for climate studies and ecological purposes since FLCs have a crucial role in supporting "fog oasis" ecosystems (Rundel and Dillon, 1998).
The regular presence of a fog climate along the coastal Atacama also facilitates highly specialized ecosystems capable of surviving scarce water availability (Rundel and Dillon, 1998; Latorre et al. 2011; Koch et al. 2019; 2020). A significant component of these coastal fog-oases is the bromeliad plant of the genus Tillandsia (see Fig. 1c and d), in particular, Tillandsia landbeckii, a well-adapted, functionally rootless desert plant that forms discrete vegetation patches on the coastal relief of the Atacama (Masuzawa, 1985; Rundel and Dillon 1998; Muñoz-Schick et al. 2001; Pinto et al. 2006; Borthagaray et al. 2010; Latorre et al. 2011; Koch et al. 2019; 2020). As T. landbeckii depends mainly on fog for both water and nutrients provision, its spatial distribution is limited to small areas covered by coastal fog with sufficient frequency (Hesse, 2012). Therefore, this species could be used as an indicator of fog-climate changes such as FLCs distribution and water input variability. Based on this assumption, Latorre et al. (2011) and Jaeschke et al. (2019) analyzed radiocarbon and stable isotopes in buried $T$. landbeckii to relate variations of fog-water input to T. landbeckii presence and distribution during the late Holocene.

Manrique et al. (2010) discussed the effects of ENSO on fog oases of coastal Peru and Chile over the last few decades. The researchers obtained contradictory results regarding ENSO influences, as increased fog (together with its potential water-input) during La Niña years could be balanced by rains or drizzle conditions characterizing El Niño years. Furthermore, different authors have related FLCs spatial changes to climatic variations, observing how such changes are leading many diverse and fragile ecosystems to a state of vulnerability, mainly due to variations of the previously granted water input (Muñoz-Schick et al. 2001; Pinto et al. 2006; Schulz et al. 2011b; Koch et al. 2020).

The insufficient understanding of the FLCs dynamics along the coastal Atacama Desert leads to a series of research questions. Within this context, the present study focuses on exploring what drives the interannual variability of FLCs frequency in the Atacama. What is the role played by ENSO concerning FLCs presence and the vertical variations of the inversion layer? What is the spatial expression of these interannual variations? How do these variations impact fog-water input to Tillandsia ecosystems? To answer these research questions, we (1) characterize and analyze the spatiotemporal distribution of FLCs over recent decades (1995-2017) to detect significant trends and variations; (2) we assess the relationship between interannual variabilities of FLCs and ENSO anomalies; and (3) we describe the relation between recent FLCs spatial changes and the current distribution of Tillandsia landbeckii. 


\section{Methods and datasets}

This study is chiefly based on fog and low clouds (FLCs) characterization using the Geostationary Operational Environmental Satellite (GOES) images. Furthermore, we compared sea surface temperature (SST) anomaly indexes to FLCs variations. Also, the marine boundary layer (MBL) vertical structure and the influence of ENSO phases on FLCs vertical distribution are both characterized using radiosonde datasets. Finally, we completed our analyses with high-resolution spatial mapping of Tillandsia ecosystems at Cerro Oyarbide. The discussion of the relationship between fog ecosystems and FLCs interannual variations is based on previous studies (Latorre et al. 2011; Koch et al. 2019, 2020).

\section{Satellite data}

We analyzed data obtained from the GOES to identify and characterize the FLCs coverage, spatial variability and significative trends. GOES satellite images were downloaded from the National Oceanic and Atmospheric Administration (NOAA) and the Comprehensive Large Array-data Stewardship System (CLASS) (https://www.avl.class.noaa.gov/saa/ products/welcome). We used GOES images from the sensors Imager 8 and 13, with a spatial resolution of 1 and $4 \mathrm{~km}$ for their visible and thermal ranges, respectively.

First, we selected GOES satellite data related to a representative area for the hyper-arid sector of the Atacama Desert, between $19^{\circ} \mathrm{S}-21^{\circ} 50^{\prime} \mathrm{S}$ and $71^{\circ} \mathrm{W}-69^{\circ} \mathrm{W}$ (Fig. 1a and c). Then, GOES images were processed and analyzed to determine the percentage of FLCs frequency during September (from 1995 to 2017) and February (from 1997 to 2017). These 2 months were selected to obtain an annual overview since they represent the high and low FLCs seasons in the study area. September presents the maximum and February the minimum monthly values of fog water yields ( $\mathrm{L}$ $\mathrm{m}^{-2}$ month $^{-1}$ ), which have been collected using a standard fog collector (SFC) (Schemenauer and Cereceda 1994) since 1997 at the Universidad Católica's Alto Patache field station

Table 1 Satellite classification for the observed daytimes. The first column indicates the algorithm used for February and September (day or night). The second column shows the thresholds used for day $\left(20^{\circ} 49^{\prime} \mathrm{S}-70^{\circ} 09^{`} \mathrm{~W}, 850 \mathrm{~m}\right.$ a. s. 1.; see Fig. 1c) (Larraín et al. 2002; Cereceda et al. 2008; del Río et al. 2018). We analyzed five images per day, captured at 03:39, 07:39, 10:39, 15:39 and 21:39 UTC (00:39, 04:39, 07:39, 12:39 and 19:39 local time, respectively). The five selected observation daytimes are representative of the advective fog daily cycle since these correspond to its usual daily maximum (night) and minimum (noon), and its inflections at dawn and sunset (Farías et al. 2005). For a more fluent reading of this paper, local time hours will be used from now on. As the availability of images does not fully cover the years and specific analyzed daytimes, we applied a search buffer of $\pm 60 \mathrm{~min}$. On some occasions, extended high clouds coverage impedes the correct detection of low clouds. For this reason, images with high cloud coverage above $20 \%$ were discarded from our analysis. In terms of representability, since the main temporal unit of this analysis is the month, a minimum of 15 images per selected daytime has been considered valid and representative of the monthly coverage. February 1995 and 1996 did not meet the minimum criteria for the number of images. Therefore, these months were excluded from our analysis. Finally, the images discarded due to the presence of high clouds correspond to 2 and $6 \%$ for February and September, respectively. For nighttime (see Table 1), images have been processed through the widely used method based on the brightness temperature differences between short $(3.8 \mu \mathrm{m})$ and long $(10.9 \mu \mathrm{m})$ infrared wavelengths (Eyre et al. 1984; Ellrod, 1995; Lee et al. 1997; Anthis and Cracknell 1999; Bendix 2002; Underwood et al. 2004; del Río et al. 2018; 2021). For the thermal difference results, we set a threshold of $-2 \mathrm{~K}$ (adapted from Lee et al. 1997) so that images presenting lower values were classified as low clouds conditions and the ones presenting higher values as cloud-free ones. Then, pixels classified as low clouds were tested through two more filters. First, we detected whether the cloud top temperature, estimated based on its brightness temperature at $10.9 \mu \mathrm{m}$ wavelength, is above or below the $273 \mathrm{~K}$ threshold (Torregrosa et al. 2015). Pixels under the temperature threshold were classified as high clouds and those above the threshold as low

\begin{tabular}{|c|c|c|c|c|c|c|}
\hline \multirow[b]{2}{*}{ Local time } & \multicolumn{2}{|c|}{ Used algorithm } & \multicolumn{2}{|c|}{ Threshold } & \multicolumn{2}{|l|}{ POD } \\
\hline & $\mathrm{Feb}$ & Sep & $\mathrm{Feb}$ & Sep & $\mathrm{Feb}$ & Sep \\
\hline $0: 39$ & Night & Night & $-2 \mathrm{~K}$ & $-2 \mathrm{~K}$ & 1 & 1 \\
\hline $4: 39$ & Night & Night & $-2 \mathrm{~K}$ & $-2 \mathrm{~K}$ & 1 & 0.967 \\
\hline 7:39 & Day & Night & $-3 \mathrm{rad}$ & $-2 \mathrm{~K}$ & 0.964 & 1 \\
\hline $12: 39$ & Day & Day & $-5.5 \mathrm{rad}$ & $-5 \mathrm{rad}$ & 1 & 0.971 \\
\hline 19:39 & Day & Night & $-5 \mathrm{rad}$ & $-2 \mathrm{~K}$ & 0.958 & 0.833 \\
\hline
\end{tabular}

and night thermal differences classification. Finally, the third column reports the probability of detection (POD) as a classification performance indicator 
clouds. Second, we performed a spatial variability analysis to validate the FLCs presence based on the homogeneity of the cloud deck. A similar validation method was successfully applied in the Namib Desert by Andersen and Cermak (2018). Furthermore, we conducted a segmentation analysis based on the variance similarity of the thermal band difference. We formed pixel groups with a minimum of $100 \mathrm{~km}^{2}$. Then, within each segmented pixel group, those with one standard deviation (SD) were classified as low clouds, while those groups with a higher than one SD were classified as no clouds, assuming that these correspond to desert soil, salt flats or local radiative fog produced inland.

For daytime (see Table 1), images were processed through change-detection techniques using the visible range and their thermal temperatures at $10.9 \mu \mathrm{m}$ wavelength (Jedlovec and Laws, 2003; Torregrosa et al. 2015). First, for the visible range $(0.55-0.75 \mu \mathrm{m})$, a clear sky image ( $100 \%$ absence of clouds) was selected for February and September at each analyzed daytime. Then, every visible image was compared to the corresponding and previously selected clear-sky one to identify, by contrast, areas with or without cloud presence. We set a threshold of \pm-5 radiance (see Table 1 ) for these results so that lower values were considered to indicate low clouds presence, while higher values were associated with a cloud-free condition. For the nighttime observations, the second method used to differentiate high and low clouds images is based on whether their brightness temperature at $10,9 \mu \mathrm{m}$ wavelength is above or below the $273 \mathrm{~K}$ threshold (Torregrosa et al. 2015).

Finally, we validated night and daytime pixels identified as low clouds for February and September 2017 by comparing them with ground truth observations (taken by the Ground Optical Fog Observation System GOFOS) (del Río et al. 2021). The correlation between GOFOS results and the corresponding satellite data showed a $96 \%$ agreement for nighttime and $93 \%$ agreement for daytime, with a root mean square error (RMSE) of 0,051 and 0.103 for February and September, respectively. In addition, Table 1 provides information concerning the applied algorithm (day or night one) and the corresponding classification thresholds for the brightness temperature (night) and optical differences (day) for each analyzed daytime. Moreover, in Table 1, we also report a performance indicator of the classification process based on the comparison between results obtained by GOFOS and GOES. Here, we included the probability of detection (POD), expressed by values between 0 and 1 , where 1 corresponds to a perfect FLCs detection (Cermak, 2012; Andersen and Cermak, 2018).

The satellite results were analyzed through two different spatial approaches to observe the FLCs' interannual variability and trends and relate these with oceanic indices. First, we defined systematic sample areas for the FLCs interannual variability. These $\sim 35 \mathrm{~km}^{2}$ sample areas keep a latitudinal distance between them of $21 \mathrm{~km}$ approximately (see red circles in Fig. 1c). From West to East, these areas are located at $65 \mathrm{~km}$ offshore, $20 \mathrm{~km}$ offshore, $5 \mathrm{~km}$ offshore, over the coastline, $5 \mathrm{~km}$ inland, $15 \mathrm{~km}$ inland and $25 \mathrm{~km}$ inland. Second, to correlate FLCs interannual variations with oceanic indices, a chain-cluster analysis was applied (Jensen 2005) to areas with a similar FLCs frequency of presence. We identified four clusters for each analyzed month (February and September) based on the FLCs presence dataset.

\section{Sea surface temperature anomalies}

Sea surface temperature (SST) data were obtained from the Oceanic Niño Index (ONI) to assess the relationship between interannual SST anomalies and FLCs variability. The analyzed index corresponds to a 3-month running mean of SST anomalies in the central Pacific zone $3.4\left(5^{\circ} \mathrm{N}-5^{\circ} \mathrm{S}\right.$; $\left.120^{\circ} \mathrm{W}-170^{\circ} \mathrm{W}\right)$. These datasets were downloaded from the Climate Prediction Center of the NOAA/ National Weather Service (https://origin.cpc.ncep.noaa.gov/products/analysis_ monitoring/ensostuff/ONI_v5.php). Then, monthly SST values were compared with monthly satellite estimates of FLCs presence for the same time period.

\section{Marine boundary layer characterization}

We characterize the marine boundary layer (MBL) vertical structure over the study area by analyzing the radiosoundings' observations from the Chilean Meteorological Service (Dirección Meteorológica de Chile). Such radiosoundings are launched daily at 12:00 UTC (08:00 local time) from the Antofagasta airport $\left(23.45361^{\circ} \mathrm{S}, 70.44056^{\circ} \mathrm{W}\right)$. To complete the MBL vertical characterization, we also analyze the sea surface temperature (SST) for the coastal Atacama Desert (19.5-24.5 S, $150 \mathrm{~km}$ offshore). The SST data were obtained from the NOAA AVHRR satellite product using the Google Earth Engine platform (Gorelick et al. 2017). We analyzed data of February and September between 1995 and 2017, which corresponds to the same period analyzed through GOES satellite imagery. We performed a two-steps analysis. First, we described the statistics of the MBL-thermal structure along with its surface and free tropospheric processes during ENSO phases. During this phase, we analyzed the SST, the MBL potential temperature $(\theta)$, the MBL height $(h)$, the thermal inversion layer $(\Delta \theta)$ and the free tropospheric thermal gradient $(\gamma \theta)$. Then, once we obtained a robust statistic of the MBL structure, we describe the vertical profiles of potential temperature $(\theta)$ and specific humidity $(q)$ during extreme ENSO phases observed in February and September. In doing so, we stretch the differences among these results to obtain an interpretation that correlates the fog frequency observed by the satellite and the MBL vertical structure observed during ENSO phases. 


\section{Results and discussions}

The presentation and discussion of the results are structured according to the three main goals set out in the introduction of this article. First, we analyze the fog and low clouds (FLCs) spatiotemporal distribution, characterizing its frequency of presence, seasonal and daily cycles, interannual variability and trends. Second, we discuss our results regarding the influence of ENSO on FLCs interannual variations. Finally, we consider how our results on recent spatiotemporal FLCs changes relate to the past and present spatial distribution of Tillandsia landbeckii.

\section{Fog and low cloud spatiotemporal distribution}

\section{Seasonal and diurnal FLCs presence cycles}

To assess FLCs seasonal and diurnal cycles, we derived average FLC presences from the Geostationary Operational Environmental Satellite (GOES) images for February and September. To study seasonal differences, all five-observation daytimes are considered. As expected for this latitude $\left(\sim 20^{\circ} \mathrm{S}\right)$, February (summer) presents the minimum Scclouds presence (e.g., $15 \%$ over the ocean areas and $4 \%$ over coastline areas), while September (early spring) is characterized by the maximum Sc-clouds occurrence (e.g., $75 \%$ over the ocean areas and $\sim 55 \%$ over coastline areas). Here, FLCs spatial distribution is highly determined by local topography considering that the prominent Coastal Cordillera (with elevations $>1300 \mathrm{~m}$ a. s. 1.) acts as a natural barrier for fog penetration. In February, in the presence of
FLCs, the base of the thermal inversion layer is higher, and the scarce FLCs summer subsistence is only occasionally able to reach farther inland (Fig. 2a). Conversely, September's dataset shows a high FLCs presence in areas between the coast and $1000 \mathrm{~m}$ a. s. 1., with values gradually decreasing for higher elevations (Fig. 2b). In September, the base of the thermal inversion layer is at $\sim 1000 \mathrm{~m}$ a. s. 1. (del Río et al. 2021); thus, a high percentage of the advective low stratus clouds is forced by the coastal ridges to stay at $1000 \mathrm{~m}$ a. s. 1. or below. At the same time, the presence of fog corridors is associated with areas with lower reliefs through which the fog access inland, consistently with the observations of Farias et al. (2005). For September, Fig. 2b shows an apparent decrease of FLCs presence from West to East. Within the first $\sim 15 \mathrm{~km}$ onshore, an area considered representative of the advective fog belt, we found an average FLCs presence of 50-20\%, characterized by high spatial variability.

Figure 3 shows the FLCs presence anomalies reported in Fig. 2 for the five-observation daytimes in February and September. These anomalies resulted from the different FLCs average between the selected hour and the five-observation daytimes. In September, we observe higher FLCs presence over the ocean and the first $\sim 15 \mathrm{~km}$ onshore at night and early morning, when surface temperatures over the ocean do not significantly contrast with the ones at land, generating calm wind conditions (Lobos-Roco et al. 2021). Within these conditions facilitating the air condensation and limiting the inland transport, the FLC deck stays steady above the ocean while it causes higher radiative cooling. During the night and early morning, the elevated MBL moisture, the ocean-land low thermal contrast and the bounded MBL
Fig. 2 Percentages of FLCs presence (a) for February and (b) for September during the study period (1995-2017).

Adapted from del Río (2020)

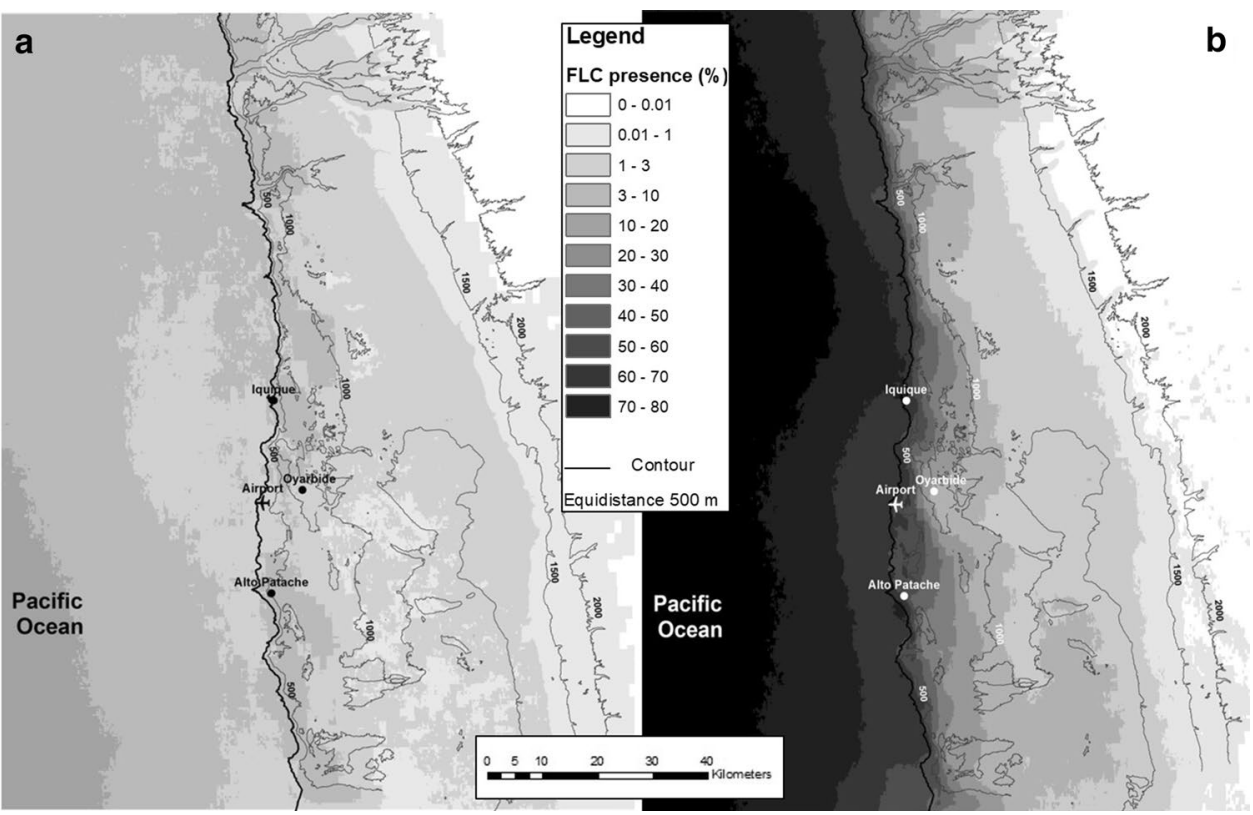




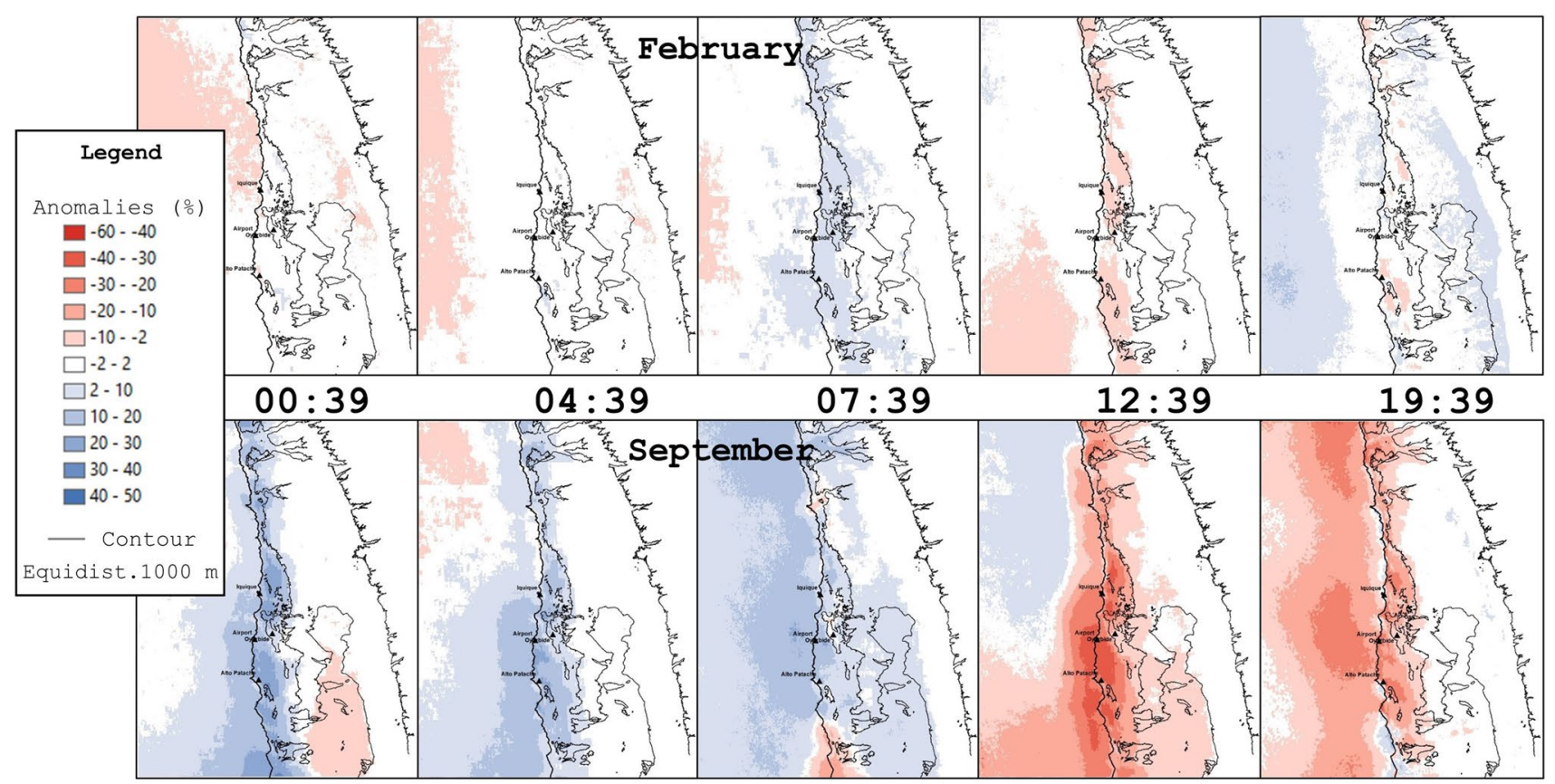

Fig. 3 February and September fog and low clouds (FLCs) presence anomalies, in percentage related to the daily mean, for the different analyzed hours (local time) within the study period (1995-2017). Red and blue shades show FLCs presence negative and positive anomalies, respectively. White shades indicate no variation

the noon-afternoon is caused by the enhanced air subsidence over the coast due to the convection created by the heating of the western slopes of the Andes.

\section{Fog and low clouds interannual variability}

altitude. Then, FLCs gradually disappear in the morning as solar radiation increases, dissipating the cloud presence during the daytime. The FLCs morning dissipation over the land is related to two processes. First, the increased land temperature (solar radiation) provoke a stratification in the interphase ocean-land that inhibits the MBL well-mixed (Lobos et al. 2018). Second, the diurnal circulation observed over the Atacama Desert returns the airflow described by Rutllant et al. (2003), increasing the subsidence and dry air advects and therefore contributing to dissipate the FLCs. From noon to the evening, southerly winds face those areas where the coastline has a southwest orientation and a high elevation. These conditions provoke the rise of air masses, which cool and condense forming orographic fog (Cereceda et al. 2002). This phenomenon can be observed in the September 19:39 image of Fig. 3. Areas with a regular presence of orographic fog have been associated with the location of unique fog oases (e.g., Alto Patache) (Muñoz-Schick et al. 2001).

In February, the maximum FLCs presence occurs during the night and especially at dawn (07:39) when lower air temperatures prevail. At noon, inland FLCs presence is almost null due to the desert heating. At the same time, very low FLCs are observed in the offshore area close to the coast. According to Rutllant et al. (2003), the FLCs absence during
The interannual variability of the FLCs presence is described under spatial and temporal perspectives for the sampling areas (offshore and inland, see Fig. 1c) throughout the study period (1995-2017). First, we analyzed the relationships among the FLCs presence variations of different sampling areas. Second, we observed the interannual variability, based on the FLCs presence monthly averages and expressed in standard deviation (SD). Table 2 reports the percentages of FLCs presence's hourly and daily means for February and September, together with their interannual variability. February presents a similarly high FLCs presence variability of the same order as the mean itself for the different analyzed areas and times because of the low FLCs presence during summer. However, the lowest interannual variations are detected at $65 \mathrm{~km}$ offshore for all the observation daytimes, while the highest interannual variations are found in nearshore areas. During September, the FLCs presence interannual variability is significantly lower than the one observed in February. Hourly and daily means of this variability present similar patterns characterized by lower variations offshore and higher variations inland. 
Table 2 February and September FLCs presence percentages $(\%)$ for the period 1995-2017 and FLCs interannual variability in standard deviations (SD), estimated based on monthly FLC averages
Fig. 4 February and September mean FLCs presence and its interannual variability. "off" and "in" are the abbreviations for offshore and inland, respectively. Adapted from del Río (2020). Note that the $y$-axes show different magnitudes of FLCs presence: the February $x$-axis (top) starts in 1997 and September (bottom) starts in 1995

\begin{tabular}{|c|c|c|c|c|c|c|c|c|c|c|c|c|}
\hline & \multicolumn{2}{|l|}{$0: 39$} & \multicolumn{2}{|l|}{ 4:39 } & \multicolumn{2}{|c|}{$\begin{array}{l}\text { Local time } \\
7: 39\end{array}$} & \multicolumn{2}{|c|}{$12: 39$} & \multicolumn{2}{|l|}{$19: 39$} & \multicolumn{2}{|c|}{$\begin{array}{l}\text { Daily } \\
\text { mean }\end{array}$} \\
\hline & $\%$ & SD & $\%$ & SD & $\%$ & SD & $\%$ & SD & $\%$ & SD & $\%$ & SD \\
\hline \multicolumn{13}{|l|}{ February } \\
\hline $65 \mathrm{~km}$ offshore & 7.1 & 5.8 & 6.1 & 5.8 & 7.9 & 6.7 & 7.9 & 7.8 & 15.9 & 7.8 & 9.0 & 5.9 \\
\hline $20 \mathrm{~km}$ offshore & 2.3 & 2.4 & 3.2 & 3.9 & 4.7 & 5.2 & 2.6 & 3.0 & 5.6 & 4.3 & 3.7 & 3.1 \\
\hline $5 \mathrm{~km}$ offshore & 1.4 & 2.1 & 2.3 & 3.3 & 4.7 & 5.9 & 2.5 & 3.2 & 4.0 & 3.5 & 3.0 & 2.8 \\
\hline Coastline & 2.3 & 2.4 & 2.9 & 3.5 & 5.5 & 6.0 & 1.6 & 2.3 & 3.8 & 3.5 & 3.2 & 2.7 \\
\hline $5 \mathrm{~km}$ inland & 3.6 & 3.0 & 4.0 & 4.1 & 7.0 & 6.5 & 1.2 & 1.8 & 3.5 & 3.2 & 3.8 & 2.8 \\
\hline $15 \mathrm{~km}$ inland & 3.1 & 2.6 & 2.7 & 2.9 & 6.6 & 6.2 & 0.7 & 1.1 & 2.4 & 2.2 & 3.0 & 2.1 \\
\hline $25 \mathrm{~km}$ inland & 0.7 & 0.9 & 0.9 & 2.0 & 3.3 & 4.9 & 0.7 & 1.0 & 2.3 & 2.1 & 1.6 & 1.5 \\
\hline \multicolumn{13}{|l|}{ September } \\
\hline $65 \mathrm{~km}$ offshore & 74.5 & 10.7 & 76.1 & 10.6 & 81.2 & 10.3 & 74.6 & 9.8 & 71.3 & 12.3 & 74.7 & 9.5 \\
\hline $20 \mathrm{~km}$ offshore & 71.6 & 11.1 & 73.5 & 11.8 & 79.9 & 9.9 & 68.4 & 10.8 & 49.6 & 12.6 & 67.6 & 9.9 \\
\hline $5 \mathrm{~km}$ offshore & 66.9 & 11.2 & 64.4 & 11.6 & 64.2 & 9.0 & 35.5 & 12.3 & 46.6 & 13.5 & 54.8 & 9.5 \\
\hline Coastline & 65.2 & 10.2 & 61.0 & 10.7 & 57.6 & 9.1 & 35.1 & 11.7 & 45.3 & 14.2 & 52.3 & 8.4 \\
\hline $5 \mathrm{~km}$ inland & 54.7 & 8.9 & 48.9 & 8.0 & 41.9 & 8.7 & 14.5 & 6.7 & 24.0 & 11.1 & 36.4 & 5.5 \\
\hline $15 \mathrm{~km}$ inland & 27.9 & 6.5 & 24.6 & 4.9 & 20.6 & 7.6 & 1.0 & 1.0 & 6.5 & 5.3 & 15.9 & 3.2 \\
\hline $25 \mathrm{~km}$ inland & 8.9 & 4.3 & 9.2 & 3.3 & 10.6 & 6.0 & 0.2 & 0.4 & 2.9 & 3.6 & 6.2 & 2.1 \\
\hline
\end{tabular}

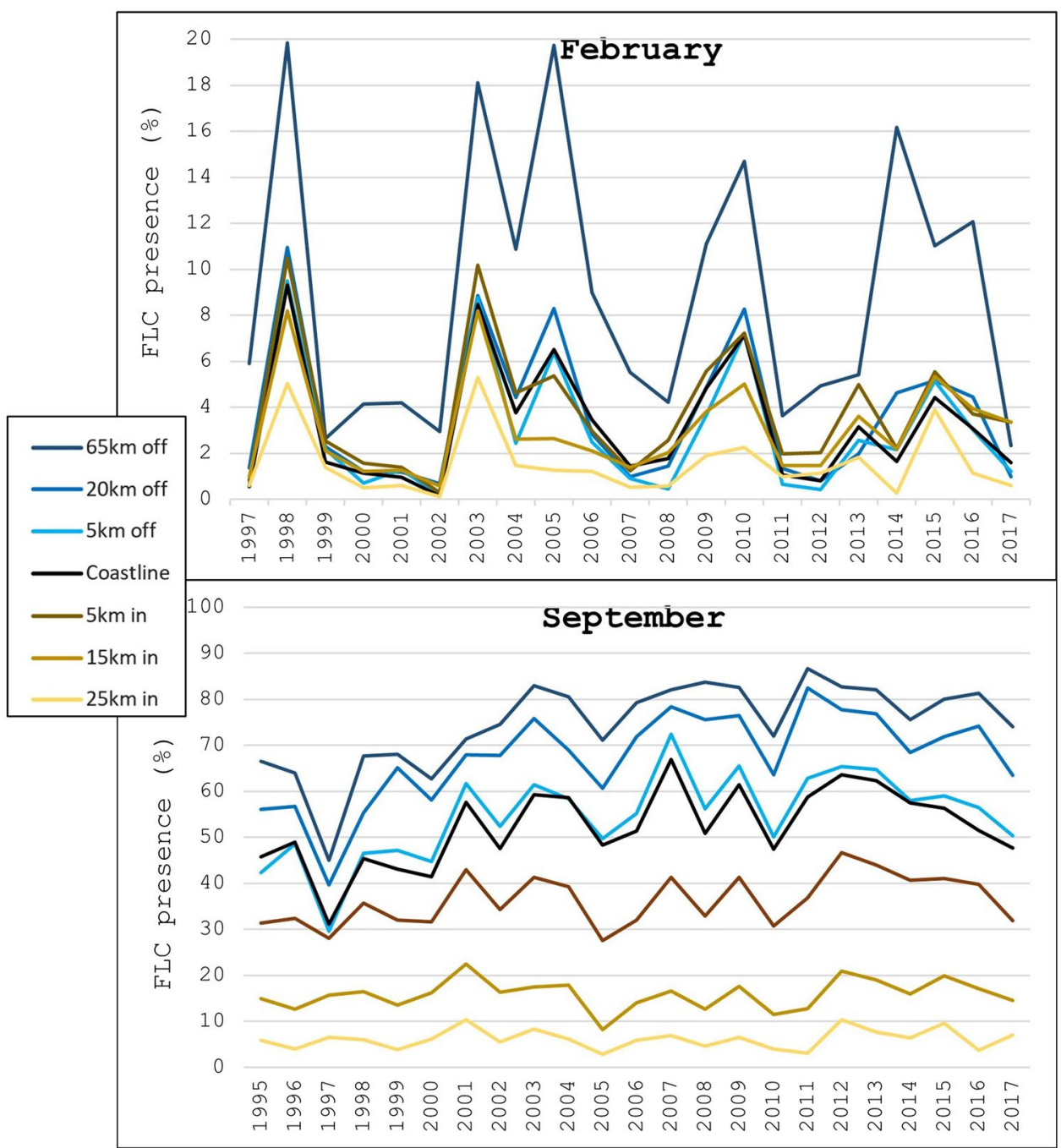


FLCs presence interannual variations of offshore and onshore areas are significantly correlated to each other in February. At the same time, the correlation between the FLCs presence $65 \mathrm{~km}$ offshore and in the other sampling areas decreases toward the coast. For example, there is a correlation of $r=+0.85$ and $r=+0.62$, with a $99 \%$ confidence level $(p<0.001)$ between observations taken $65 \mathrm{~km}$ offshore and $5 \mathrm{~km}$ offshore and $25 \mathrm{~km}$ inland, respectively (Fig. 4). Here, the higher altitude of the thermal inversion layer (TIL) during February generates a scarce FLCs presence and the influence of the relief over FLCs spatial distribution is lower. In Fig. 4, February's results show that the highest values for FLCs presence occur in the years 1998, 2003, 2005, 2010, and 2014-2016, while the lowest ones are observed in the years 1999-2002, 2008, 2011-2012 and 2017.

For September, no significant correlations emerged between FLCs presence in onshore areas (especially those located $15 \mathrm{~km}$ and $25 \mathrm{~km}$ inland) and offshore ones. Moreover, minimum and maximum FLCs frequency years do not correspond for onshore and offshore areas (see Fig. 4). September also shows a large interannual variability, but a clear FLCs presence trend is observed at the same time. This trend moved from a period of lower (1995-2000) to one of maximum (2007-2012) FLCs presence, and finally decreased (2013-2017) (Fig. 4).

FLCs interannual variations observed for different daytimes in February (Fig. 5) show slight differences compared to the FLCs daily mean (Fig. 4). Results referring to all the observed daytimes show that the most significant FLCs average variability is found in areas close to the coast. In the ocean (20 and $5 \mathrm{~km}$ offshore areas), the highest FLCs interannual variability is detected at 04:39 and the lowest at 19:39. Over the coastline and $5 \mathrm{~km}$ onshore, the highest FLCs interannual variability occurs at noon and the lowest is again at sunset. This pattern recurs for 15 and $25 \mathrm{~km}$ inland areas. The years in which maximum and minimum FLCs presence occurred are characterized by a high agreement among their FLCs daily observations. As expected, the FLCs interannual variability observed for the five selected daytimes in September shows similar patterns compared to the correspondent daily mean, with a lower relative variation over the ocean and near shore areas, and higher relative variation in the inland ones (see Fig. 5). Despite the FLCs variations characterizing the sampled daytimes, the variability was higher at noon and sunset for all the sample areas, particularly from $5 \mathrm{~km}$ offshore toward the inland. Conversely, lower FLCs variability was observed at dawn and night.

\section{Fog and low clouds trends}

The FLCs satellite identification for September and February within the study period (1995-2017) provides us evidence to determine FLCs presence tendencies. Based on the cluster areas (shown in Fig. 7) and using daily averages, it is possible to observe differing trends between observations corresponding to the ocean surface, nearshore areas (both onshore and offshore), and inland ones.

In September, by applying linear regression, FLCs daily presence average changes over the ocean (cluster 1) showing a weak, yet statistically significant, positive trend (1\%/ annual; $p<0.001)$. The same trend is also present in cluster 2 (0.9\%/annual; $p<0.001)$, which mainly covers the nearshore areas, both offshore and onshore. This trend reveals that the average FLCs presence in clusters 1 and 2 increased by $20 \%$ between 1995 and 2017. In the onshore and inland areas (clusters 3 and 4 ), the trend showed again to be weak and positive ( $0.8 \% /$ annual; $p<0.002)$. However, cluster 4 is not expected to be statistically significant due to the continuous very low FLCs presence in this area.

Figure 6 shows the FLCs presence trend based on monthly averages for the study period, using the Theil-Sen method for a pixel-by-pixel scale of analysis. Within this figure, differences are visible between ocean areas, nearshore areas and inland ones. Figure 6 also shows that between the coastline and $1000 \mathrm{~m}$ a. s. 1., a weak-positive trend prevails, whereas above this altitude (1000 $\mathrm{m}$ a. s. 1.) some limited areas present a weak-negative trend (e.g., over the Oyarbide Tillandsia field). These results, consistent with those described by Schulz et al. (2011a), highlight the interplay between FLCs presence trends, the thermal inversion layer altitude and the topography of the study area. These findings are particularly relevant when considering that the areas characterized by a decreasing FLCs trend, corresponding to the location of Tillandsia fields, might be affected by a decreasing presence of fog, provider of water and nutrients inputs. Figure 6 also reveals that the areas with a weak and negative trend are not found along the entire $1000 \mathrm{~m}$ contour line, but rather in those areas where the altitudes near $1000 \mathrm{~m}$ a. s. 1. are closer to the coast and with an S-SW orientation, opposite to the predominant wind direction (Muñoz and Garreaud, 2005). The latter highlights the influence of these factors on fog occurrence and, consequently, the presence and geographical distribution of Tillandsia fields (Pinto et al. 2006).

In February, a higher FLCs fragmentation indicates low FLCs presence and less regular cloud deck formation. This results in an almost null FLCs presence trend over the study period, with no statistical significance in any studied areas (ocean, nearshore and inland ones).

The null FLCs presence trends detected during February within the different cluster areas are consistent with those observed by Muñoz et al. (2016) at the Iquique Airport, where FLCs summer presence results equivalent to its average over the last 30 years. A similar condition occurs during winter-early spring when we detected a weak-positive trend over the ocean and in nearshore areas, 


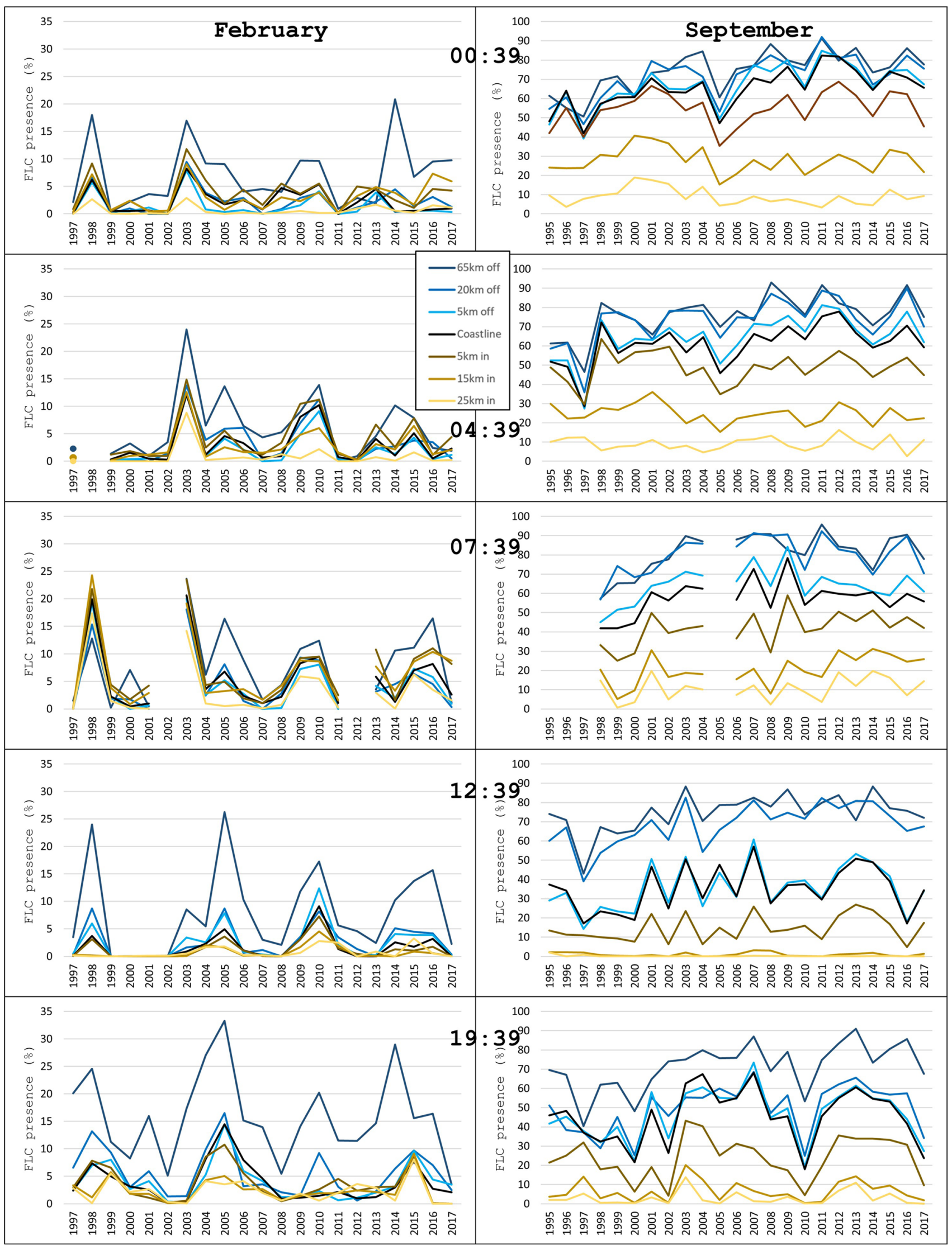


४Fig. 5 February and September analyzed daily hourly-means of fog and low clouds (FLCs) frequency and its interannual variability. "off" and "in" are the abbreviations for offshore and inland, respectively. Adapted from del Río (2020)

consistently with the Airport observations. Moreover, in agreement with our results, Seethala et al. (2015) showed an increase of the low clouds annual average trend in the southeast Pacific (SEP) for 1984-2009 based on global satellite data. Despite the accordant results obtained by the latter study, these should be interpreted with caution, as the research mainly addressed low clouds over the Pacific Ocean on a synoptic scale, not necessarily capturing the coastal-land influences on these clouds. Conversely, the studies of Schulz et al. (2011a) and Quintana and Berrios (2007), also based on the Iquique Airport observations, show negative trends in cloud cover. However, these researchers applied different methodological approaches, based on observations made at specific daytimes, and using different criteria for what we have defined as "low cloud" in this article. On the other hand, they analyzed a more extended time series compared to our study, including the decade of the 1970s when a significant increase in low cloud presence occurred.

We have not found prior results to compare with the FLCs cover weak-negative trend that we observed above $\sim 1.000 \mathrm{~m}$ a. s. 1. in the Coastal Cordillera during September. In this month, while FLCs presence increases in the ocean and nearshore areas, it decreases in higher reliefs. In the area next to the Oyarbide Tillandsia fields, del Río et al. (2021) estimated a mean altitude of the thermal inversion layer of $1060 \mathrm{~m}$ a. s. 1 . with a $1000 \mathrm{~m}$ a. s. 1 . mode and $\pm 150 \mathrm{~m}$ of variability for September 2016 and 2017. Such results, derived by the analysis of satellite images, suggest a decreased FLCs presence for these areas. However, local factors such as topography, wind speed and wind direction can influence fog distribution in ways that are still not sufficiently understood. Furthermore, these factors could counteract a decline in the thermal inversion layer. The dieback in fog-dependent vegetation observed by Schulz et al. (2011b) is a possible evidence of this negative trend since less fog coverage leads to less water input and a consequent decreasing presence of these species.

The resulting trends must be interpreted in a decadal time frame during which La Niña cold conditions have characterized the Pacific basin considering that both the Interdecadal Pacific Oscillation (IPO) and the Pacific Decadal Oscillation (PDO) indexes show a cooling climate since the late 1990s (Sohn et al. 2013; Witiw and LaDochy, 2015). La Niña pattern entails oceanic-atmospheric conditions characterized by an intensification of the SEPA, which is related to higher air subsidence in the subtropical region, a strengthening of the thermal inversion layer, a shallower MBL, and cooler temperatures (Garreaud et al. 2008; Muñoz et al. 2016). Various authors have observed physical variations caused by La Niña. For example, Falvey and Garreaud (2009) and Vuille et al. (2015) documented a cooling of surface temperatures along the northern Chilean coast during the last decades. This phenomenon is associated with a strong vertical stratification of air temperatures over central and northern Chile and implies an intensified thermal inversion layer, determining increased temperatures above and cooler ones below it. These conditions are propitious for FLCs formation and therefore consistent with the tendency we observed.

Additionally, we must consider the influence of global warming on these trends. Seethala et al. (2015) suggest that the observed SEP FLCs formation trends may be related to natural variations and not necessarily to systematic responses to global warming. Contrarily, Vuille et al. (2015) suggest that the time and magnitude similarities between temperature changes and trends in the Andes and the west coast of South America are unlikely to occur due to natural cycles only and are better correlated with an average rise in global warming. Although various climate models' projections for the coastal Atacama do not correctly detect the recent MBL cooling (Falvey and Garreaud 2009), nor properly characterize its physics and dynamics (Seethala et al. 2015), climate models agree that the temperature over the thermal inversion will continue to rise (Vuille et al. 2015) and that the SEPA will continue to strengthen (Falvey and Garreaud., 2009). Higher temperatures above the thermal inversion layer, together with an enhanced SEPA, would imply a strengthening of the inversion layer itself, leading to increased stability between the atmosphere layers. Consequently, favorable conditions for the FLCs formation might persist or increase. This assumption could only be confirmed by analyzing longer time-series datasets.

\section{ENSO influences on FLCs variability}

In this section, we describe and discuss ENSO influence on FLCs presence and the MBL growth in summer and winter, two seasons corresponding to the lowest and the highest FLCs occurrence, respectively.

\section{ENSO influences on FLCs presence}

To analyze the SST influence on the FLCs formation, we assessed the relationship between ONI (an indicator of ENSO phases) and the estimated FLCs presence within the cluster areas (indicated in Fig. 7). February FLCs interannual variability is closely related to ENSO 3.4 SST anomalies, especially in cluster areas 1 and 2, which correspond to the ocean and onshore areas close to the coast (Fig. 7a). The results related to these areas show significant correlations between FLCs presence and ONI (Pearson's: $r=+0.66$ 
Fig. 6 Median trend slopes of daily mean FLCs frequency for September (1995-2017). Weak and negative trends are mainly observed in areas above the $1000 \mathrm{~m}$ a. s. 1., where most of the Tillandsia fields are located (e.g., Oyarbide)

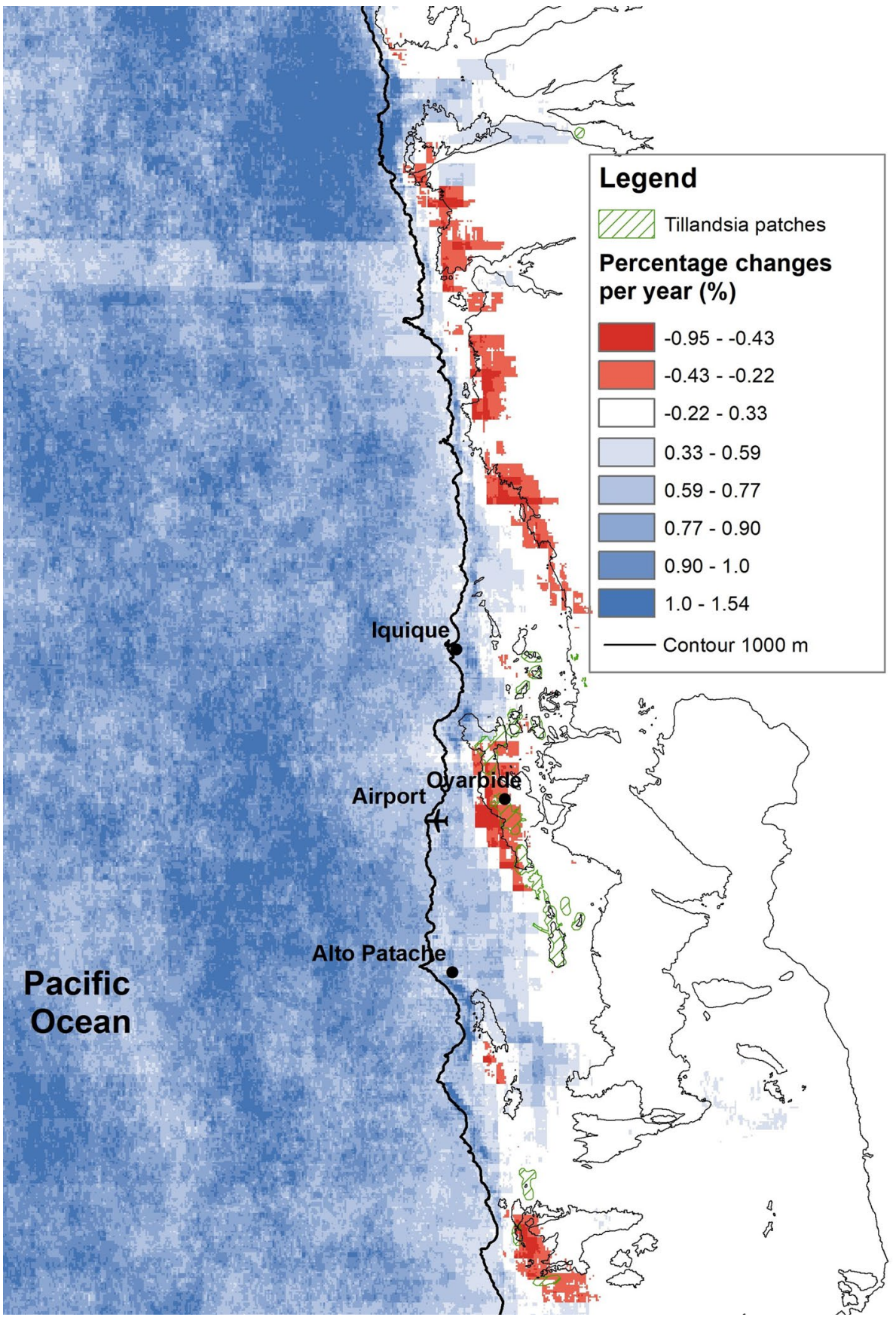

and $r=+0.68$, respectively, with a $99 \%$ confidence level; $p<0.001$; Kendall's rank: $\tau=+0.36$; $p<0.02$ and $\tau=+0.49 ; p<0.002$, respectively). The results concerning cluster areas 3 and 4 do not show the same significant correlations, which is to be expected due to a very-low-to-null FLCs presence. We observed positive correlations between FLCs presence and ONI with the ENSO warm phase (El Niño), which is related to higher FLCs presence over the ocean and coastal areas. Conversely, under an ENSO cool phase (La Niña), we detected a lower FLCs presence. The maximum FLCs presence occurred in ENSO warm phases characterized by different intensities, for example, the ones reported in the years 1998 (strong), 2003 and 2005 (weak) and 2010 (moderate). On the other hand, minimum FLCs presence occurred during ENSO (-) years which also present varying intensities, for example, the ones of the years 1999-2000, 2008 and 2011 (Moderate), 2001 and 2012 (weak), and even of some neutral years, such as 2002 and 2017.

Despite the high correlation between ENSO and FLCs presence during February, there are few years when the same correlation is not significant, although this result varies 


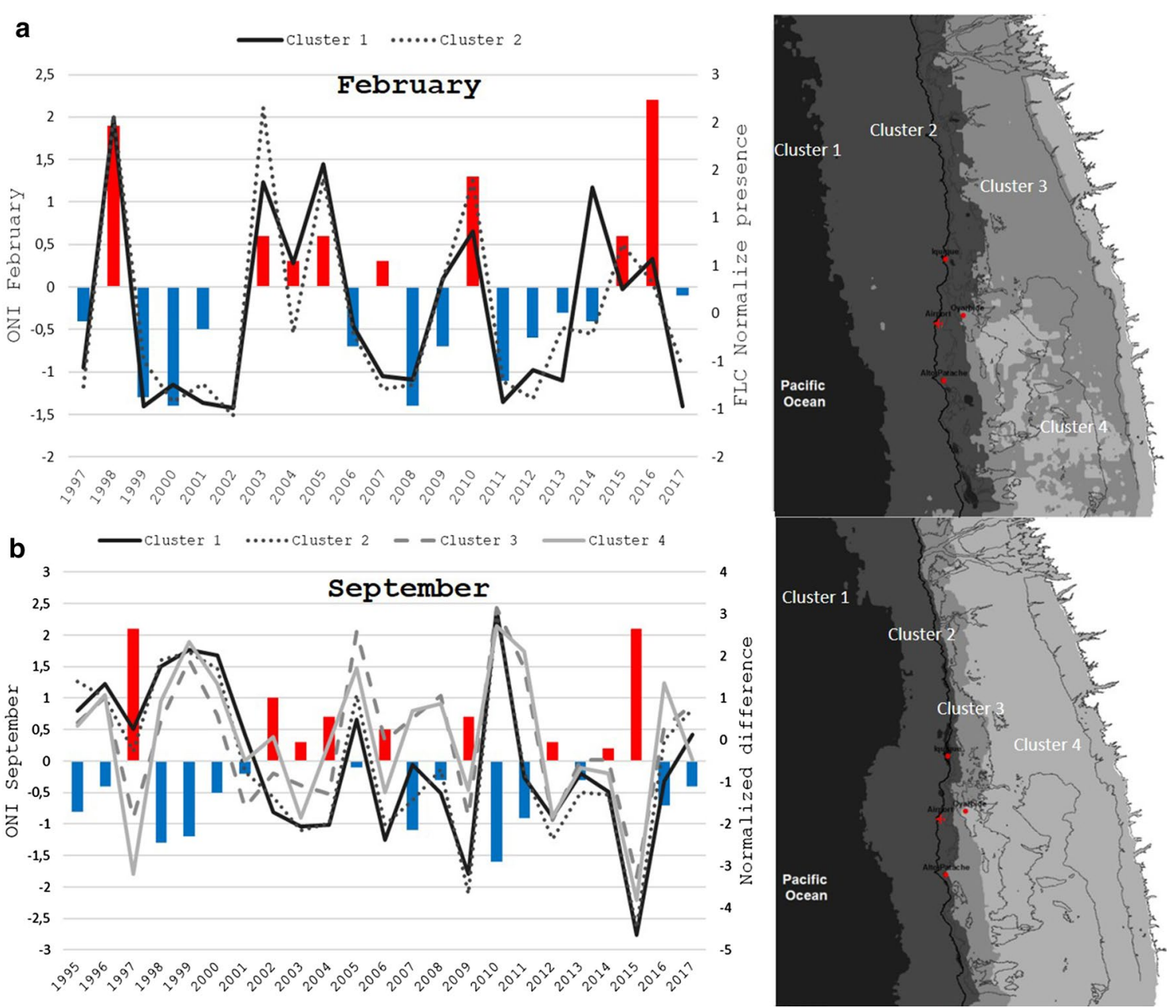

Fig. 7 Oceanic Niño Index (ONI) SST anomalies at 3.4 zone within the analyzed period. The red bars correspond to El Niño (ENSO warm) phases and the blue bars correspond to La Niña (ENSO cool) phases. a Fog and low clouds (FLCs) presence during February for clusters 1 and 2. The FLCs presence for both clusters was normalized to compare it with the ONI index. Cluster areas are

according to different cluster areas. For example, cluster 1 shows a very high FLCs presence during 2014, not seen in other years with a neutral ENSO phase. However, FLCs presence significantly decreases in cluster 2 , showing values more in line with FLCs frequencies characterizing a neutral ENSO phase. In 2016, despite a very strong ENSO warm phase, FLCs presence was not as significant as during other ENSO warm years.

We performed a linear regression for all the analyzed years to quantify the relationship between the ENSO 3.4 zone and the coastal Atacama FLCs presence in clusters 1 and 2 for February (see Fig. 8a). This regression indicates that ENSO anomalies explain $~ 50 \%$ of the interannual FLCs presence variance during summer $(p<0.001)$. Results related to cluster 1 present a determination coefficient $\left(R^{2}\right)$ of 0.36 , but if the year 2014 is not considered, this coefficient defined according to February FLCs mean; b FLCs presence during September for clusters 1, 2, 3 and 4. The FLCs presence for the four clusters corresponds to the normalized difference between FLCs presence and IPO. Cluster areas are defined according to September FLCs mean

increases to $R^{2}=0.51$. For cluster 2 , this coefficient amounts to $R^{2}=0.49$ (included the year 2014). Such a significant correlation suggests the existence of a potential causal relation between ENSO phases and coastal Atacama FLCs presence during February (summer), both offshore and onshore.

During September, the interannual FLCs presence variability does not significantly correlate with ENSO SST anomalies in zone 3.4. Correlation and regression analyses led to null or statistically insignificant results. The observed FLCs presence tendency (see Fig. 4) is characterized by a first period of lower FLCs presence, which then increases until reaching a peak between 2007 and 2011 approximately, and finally decreases until 2017. Observing this tendency, we derived two conclusions: (1) the trend is nonlinear; (2) at the decadal scale, the Pacific Ocean presents long-term SST oscillations which cycles can last from 20 to 30 years. 
Fig. 8 Scatter plot of FLCs and normalized FLCs versus ONI SST anomalies for (a) February and (b) September. ONI anomalies $<-0.5^{\circ} \mathrm{C}$ indicate weak-to-strong La Niña ENSO cool phases, whereas ONI anomalies $>0.5^{\circ} \mathrm{C}$ indicate weak-to-very-strong El Niño ENSO warm phases. Dashed lines represent the fitted linear regressions

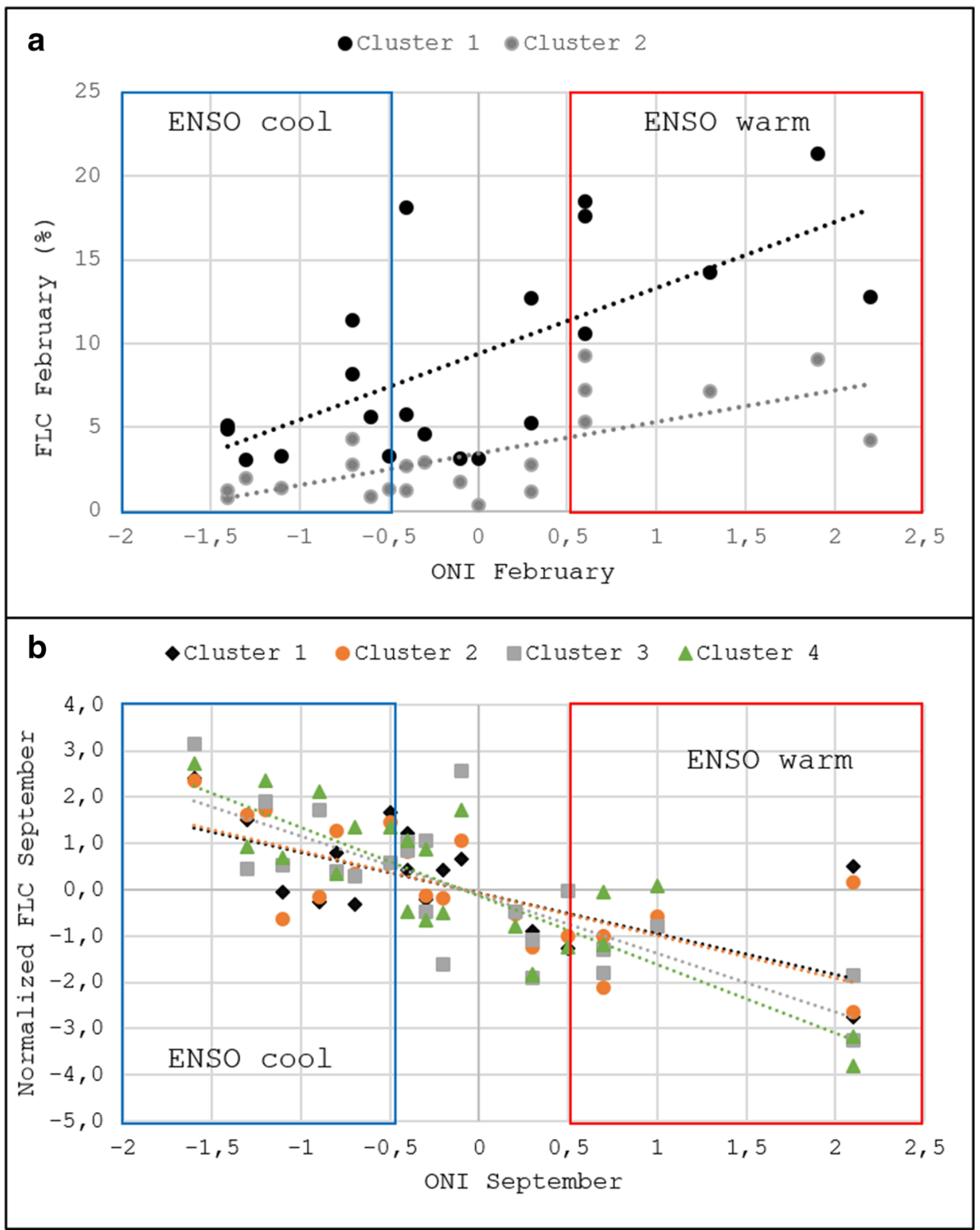

One of the indices that estimate the SST decadal variability is the Interdecadal Pacific Oscillation (IPO) (Power et al. 1999). In this sense, the observed FLCs trend presents very similar patterns to IPO during the studied period (Meehl et al. 2021).

During recent decades, a La Niña tendency has predominated (Falvey and Garreaud 2009; Schultz et al. 2011a; Muñoz et al. 2016) with a peak around 2010-2011 coinciding with the maximum FLCs presence of the study period. Currently, this condition is beginning to shift toward an El Niño cycle (Meehl et al. 2021). Within this context, and intending to extract the decadal climatic signal from September FLCs interannual variability, we normalized both variables (the FLCs presence estimated with GOES and the IPO) based on the unfiltered monthly time series (Henley et al.
2015). Additionally, we subtracted the low-frequency IPO signal from the FLCs presence normalized record. Finally, we performed statistical analyses of the high-frequency variability of the FLCs record for the different cluster areas. The results of the correlation analyses show a strong and significant inverse relationship between FLCs and the ENSO SST anomalies in ENSO zone 3.4 (see Fig. 7b). ONI shows a significant and strong inverse correlation $(r=-0.69$; $r=-0.70 ; r=-0.78$ and $r=-0.84$, for cluster $1,2,3$ and 4 , respectively) with a $99 \%$ confidence level. Despite these statistically significant results, the ones related to cluster 4 should be cautiously interpreted due to its high interannual variability (of $\sim 50 \%$ ) caused by the very-low-to-null FLCs presence characterizing these areas. 
Figure $7 \mathrm{~b}$ shows that the ENSO cool phase is related to higher FLCs presence over the ocean and coastal areas. Conversely, under an ENSO warm phase, we observed a lower FLCs presence, revealing an opposite response to ENSO phase anomalies between summer and winter-early spring. Despite the resulted high correlations, the relationship between the interannual FLCs variations and ENSO phases present observable magnitude differences between areas of oceanic predominance (clusters 1 and 2) and inland ones (clusters 3 and 4). This correlation is stronger in nearshore and inland areas. In the first 2 clusters (Fig. 7), the maximum FLCs presence occurred in ENSO cool phases characterized by different intensities, as in the years 1995-1996 (weakneutral), 1998-1999 (moderate), 2000 (weak) and 2010 (strong), and even in the neutral years 2005 and 2016-2017. In clusters 3 and 4, the maximum FLCs presence occurred during these same years, with the addition of high FLCs events also in 2007-2008 (moderate-to-neutral ENSO phases). On the other hand, the minimum FLCs presence occurred during ENSO warm years, once more characterized by varying intensities. In this case, it is worth mentioning the FLCs occurrence in different cluster areas for the years 2002-2004, 2006 and 2009 (moderate-to-weak ENSO intensity), together with 2015 (very strong ENSO intensity), the year presenting the lowest FLCs presence, and also some neutral years, such as 2012-2013 and 2014.

To study the described correlation between the ENSO zone 3.4 and FLCs presence during September in the coastal Atacama's different cluster areas, we fitted a linear regression for all the analyzed years (see Fig. 8b). This regression indicates $(p<0.001)$ that ENSO anomalies cause almost $50 \%$ of the variance in the interannual FLCs frequency during winter-early spring in the oceanic clusters (1 and 2), with an $R^{2}$ of 0.48 and 0.49 , respectively. For clusters 3 and $4, R^{2}$ significantly increases until reaching values of 0.61 and 0.71 , respectively. Among these, cluster 3 corresponds to the most interesting area in terms of fog presence, variability, and Tillandsia presence. Here, ENSO phases correspond to $61 \%$ of the FLCs interannual variance, suggesting the existence of a potential causal relationship between ENSO (warm and cool) phases and the high FLCs season in the coastal Atacama. This assumption is particularly relevant with regard to the potential effects of the ENSO phenomenon on fog-dependent ecosystems.

We performed statistical analyses to describe the relationships between interannual FLCs variability and SST anomalies in areas closer to the Atacama for February and September. In this way, we correlated FLCs presence with SSTs for ENSO zone 1+2 (coastal Equatorial Pacific) and along the coast of the Atacama. For doing it, we used SST monthly averages estimated by Vargas (2019) based on MODIS product (L3) for the period 2002-2017 (the average SST was extracted for the area between the coastline and $120 \mathrm{~km}$ offshore, referring to the northern and southern boundaries of the processed GOES imagery). Our analysis revealed no significant relationship between FLCs (with and without the IPO decadal sign influence) and the ENSO zone $1+2$. Likewise, no significant relationship was identified between FLCs and Atacama SSTs at the different analyzed daytimes. Therefore, during February and September local SSTs have no direct association with FLCs in the coastal Atacama. This finding emphasizes that FLCs formation is primarily related to regional rather than local dynamics. del Río et al. (2018) found a low $(r=-0.40)$ but significant relationship between the local SST and the fog water yields collected in the Alto Patache station, especially during summer and under ENSO $(+)$ conditions. Our analysis suggests that the relationship between coastal SST and fog water is mainly explained by two interactions. First, the coastal SST affects the MBL temperature budget (Vuille et al. 2015) and its vertical structure (Garreaud et al. 2008). Second, this MBL structure affects the Liquid Water Content (LWC) of the Sc-cloud since cold (warm) conditions lead to low (high) LWC. This alteration affects the fog water yields significantly.

\section{ENSO phases influence on the marine boundary layer growth}

To complete the study of the FLCs presence interannual variability at the coastal Atacama Desert, we analyze the vertical structure of the marine boundary layer during different ENSO phases.

Figure 9 shows the factors affecting the MBL structure: SST, mean MBL potential temperature $(\theta)$, inversion layer $(\Delta \theta)$, free troposphere thermal gradient $(\gamma \theta)$ and boundary layer height $(h)$. These data were measured at Antofagasta Airport $\left(23.45361^{\circ} \mathrm{S}, 70.44056^{\circ} \mathrm{W}\right)$ from 1995 to 2017 during the representative summer (February) and winter (September) months under warm, cool and neutral phases of ENSO. The ENSO phases are classified by the Oceanic El Nino Index (ONI), which describes SST anomalies in the 3.4 region. We name it a "cool ENSO phase" when ONI is $<-0.5 \mathrm{C}$, a "neutral ENSO phase" when ONI stays between $-0.5 \mathrm{C}$ and $0.5 \mathrm{C}$, and a "warm ENSO phase" when $\mathrm{ONI}$ is $>0.5 \mathrm{C}$.

During summer conditions (February), we do not observe significant differences for the MBL height $(h)$ between different ENSO phases. However, during warm ENSO phases, $h$ presents higher variability than in cool ones. As expected, during February warm ENSO phases, SSTs are $2 \mathrm{~K}$ higher than during cool ENSO phases and $1 \mathrm{k}$ higher than during neutral ENSO ones. Even though this SST rise does not substantially alter the MBL heat budget (theta), it significantly affects the thermal inversion that results in being $1.5 \mathrm{~K}$ warmer than during cool ENSO phases. Finally, the free tropospheric thermal gradient observed during warm 

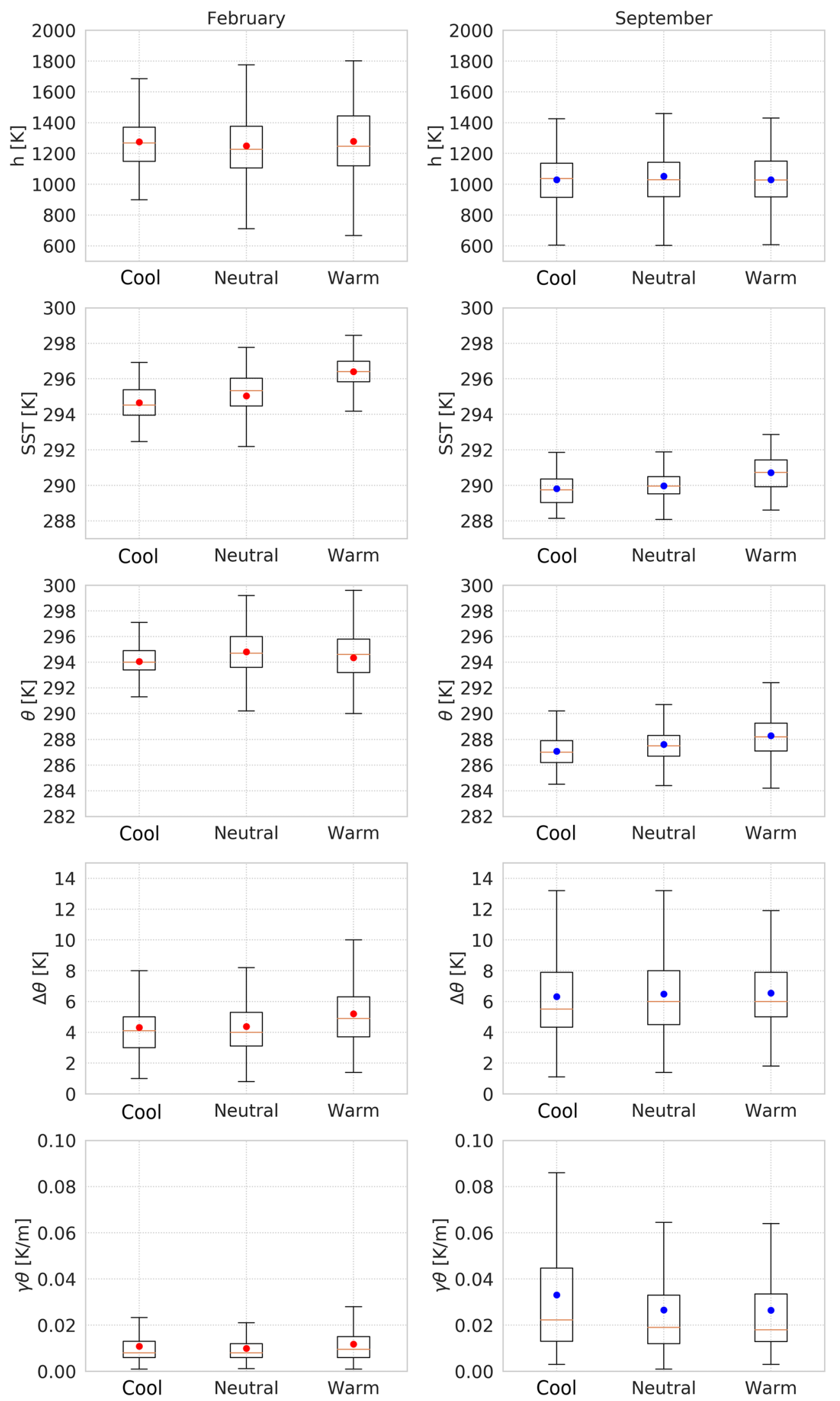
४Fig. 9 Statistics of marine boundary layer vertical structure for cool, neutral and warm ENSO phases during February (left panels) and September (right panels) from 1995 to 2017. The data were obtained from the radiosondes measured at Antofagasta Airport $\left(23.45361^{\circ} \mathrm{S}\right.$, $\left.70.44056^{\circ} \mathrm{W}\right)$ every day at 12:00 UTC (08:00 local time)

ENSO phases is slightly higher than during cool ones. During summer, the somewhat higher free tropospheric thermal gradient and inversion layer promote Sc-cloud formation and maintenance.

On the contrary, under winter conditions (September), the MBL height does not change among different ENSO phases. However, as expected, we observe an increase of $1 \mathrm{~K}$ in the SST during warmer ENSO phases, leading to a slightly warmer MBL heat budget. The thermal inversion layer observed during September under warm ENSO phases does not shows significant changes. However, during cool and neutral phases, the inversion layer reaches its maximums values $>12 \mathrm{~K}$. Under winter conditions, during cool ENSO phases, we observed that the free tropospheric thermal gradient doubles $(0.045 \mathrm{~K} / \mathrm{m})$ compared to the warm ENSO phases. This variation diminishes the exchange between the MBL and the free troposphere, promoting Sc-cloud formation and maintenance. Our results agree with the ones obtained by Muñoz et al. (2011) for the same study area, where the authors describe the climatology of the MBL from 1979 to 1997 . Also, our findings partly agree with studies based on observations obtained in the Northeast Pacific Ocean (Wood, 2012; Schubert et al. 1979). However, our ABL height observations differ from these reference studies due to the strong influence of topography characterizing our study site.

To stretch the differences of the MBL structure during cool, neutral and warm ENSO phases observed in February (Summer) and September (Winter), we described (Fig. 10) the vertical profiles of potential temperature $(\theta)$ and specific humidity $(q)$ (12:00 UTC-08:00 LT) measured at Antofagasta Airport $\left(23.45361^{\circ} \mathrm{S}, 70.44056^{\circ} \mathrm{W}\right)$ during the most extreme ENSO phases. These extreme ENSO phases correspond to the highest, lowest, and the most neutral SST anomalies in the ONI index observed from 1995 to 2017 during February and September.

For September, Fig. 10a shows that MBL well-mixed $\theta$-profiles amount to $285 \mathrm{~K}$ during cool and neutral ENSO phases and to $288 \mathrm{~K}$ during warm ENSO phases. The three inversion layers $(\Delta \theta)$ present more differences than the mixed layer values. The cool ENSO phase presents an $\Delta \theta$ of $13 \mathrm{~K}$ with $h \sim 1000 \mathrm{~m}$.

Conversely, the warm ENSO phase shows a slightly weaker $\Delta \theta$ than the cold one $(10 \mathrm{~K})$ a hundred meters higher $(h \sim 1100 \mathrm{~m})$. Finally, the neutral ENSO phase presents a $\Delta \theta$ similar to the warm one, yet at a lower height $(h \sim 900 \mathrm{~m})$. These thermal inversion layer values are consistent with the statistics reported in Fig. 9. The three troposphere vertical thermal gradients shown in the $\theta$-profiles are similar among them, with values around $0.035 \mathrm{~K} \mathrm{~m}^{-1}$. The structure of the $q$-profiles shown in Fig. 10b agrees with the $\theta$-profiles one. During warm ENSO phases, the MBL is well mixed and the moistest, with values ranging from 7 to $9 \mathrm{~g} \mathrm{~kg}^{-1}$. Likewise, during cool and warm ENSO phases, the inversion layer (Fig. 10b) can be found at 1000 and $1200 \mathrm{~m}$, respectively. Finally, lapse rates of $-0.001 \mathrm{~g} \mathrm{~kg}^{-1} \mathrm{~m}^{-1}$ in $q$-profiles are equally observed in the three ENSO phases.

During February, the state of the MBL is opposite to the winter one. Figure 10c shows less mixing in the MBL, reporting mixed layer values of $0.002 \mathrm{~K} \mathrm{~m}^{-1}$. Likewise, the inversion layer is remarkably weaker in the summer than winter, with values around $\Delta \theta \sim 5 \mathrm{~K}$ which are challenging to identify due to the lower MBL mixing. However, the height of the inversion base observed in February is higher during the warm ENSO phase $(h \sim 1250 \mathrm{~m})$ than during the cool one $(h \sim 750 \mathrm{~m})$. Finally, during summer the free troposphere thermal gradient is low in all the three ENSO phases, with values around $0,005 \mathrm{~K} \mathrm{~m}^{-1}$. The latter is related to the summer decreasing subsidence (Fig. 9). Figure 10d shows the MBL q-profiles in each of the three ENSO phases. These profiles present a similar but moister mixing than in winter $\left(\sim 11 \mathrm{~g} \mathrm{~kg}^{-1}\right)$. Here, the inversion layer observed in q-profiles (Fig. 10d) is less defined than in $\theta$-profiles. However, we find the MBL at $1300 \mathrm{~m}$ during the warm ENSO phase and at $750 \mathrm{~m}$ during the cool one.

The MBL shows an opposite behavior concerning ENSO phases between September and February. This contrast is related to the FLCs frequency along the coastal Atacama Desert observed by the GOES satellite. For example, during September cool ENSO phases prompt the strongest and best-defined $\Delta \theta$. This phenomenon contributes to increasing fog frequency in two ways. First, the thermal inversion layer restricts the MBL below the top of the coastal mountains (Rutllant et al. 2003), avoiding entrainment from the free troposphere and the MBL mixing with dry inland air masses. Second, it enhances the condensation over the ocean due to low sea surface temperatures. In contrast, the warm ENSO phases in September might generate less fog frequency due to the decreased inversion layer strength, leading to more entrainment and less condensation over the ocean.

During February, warm ENSO phases have an opposite effect compared to the one observed in September, producing increased fog frequency as cool ENSO phases do during September. This change is explained by a combination of SST, subsidence and topographic factors. First, under warm ENSO phases, the MBL and the free troposphere are the moistest and the warmest. Therefore, the warmest and moistest marine air masses induce the MBL to grow and reach the coastal summits (1300 m a. s. 1.). Simultaneously, the coastal summits force MBL air masses to lift, cooling down and 
Fig. 10 Marine boundary layer vertical profiles obtained in Antofagasta Airport during the warmest, coolest and most neutral ENSO phases observed in February and September (from 1995 to 2017). a Potential temperature and b specific humidity vertical profiles of September 1st, 2015 (warm, ONI =2.2), 7th, 2010 (cool, ONI $=-1.6)$ and 4th, 2005 (neutral, ONI $=-0.1$ ). c) Potential temperature and (d) specific humidity vertical profiles of February 1st, 2016 (warm, ONI =2.1), 2nd, 2008 (cool, ONI = 2.2), and 3rd, 2002 (neutral, $\mathrm{ONI}=0$ )
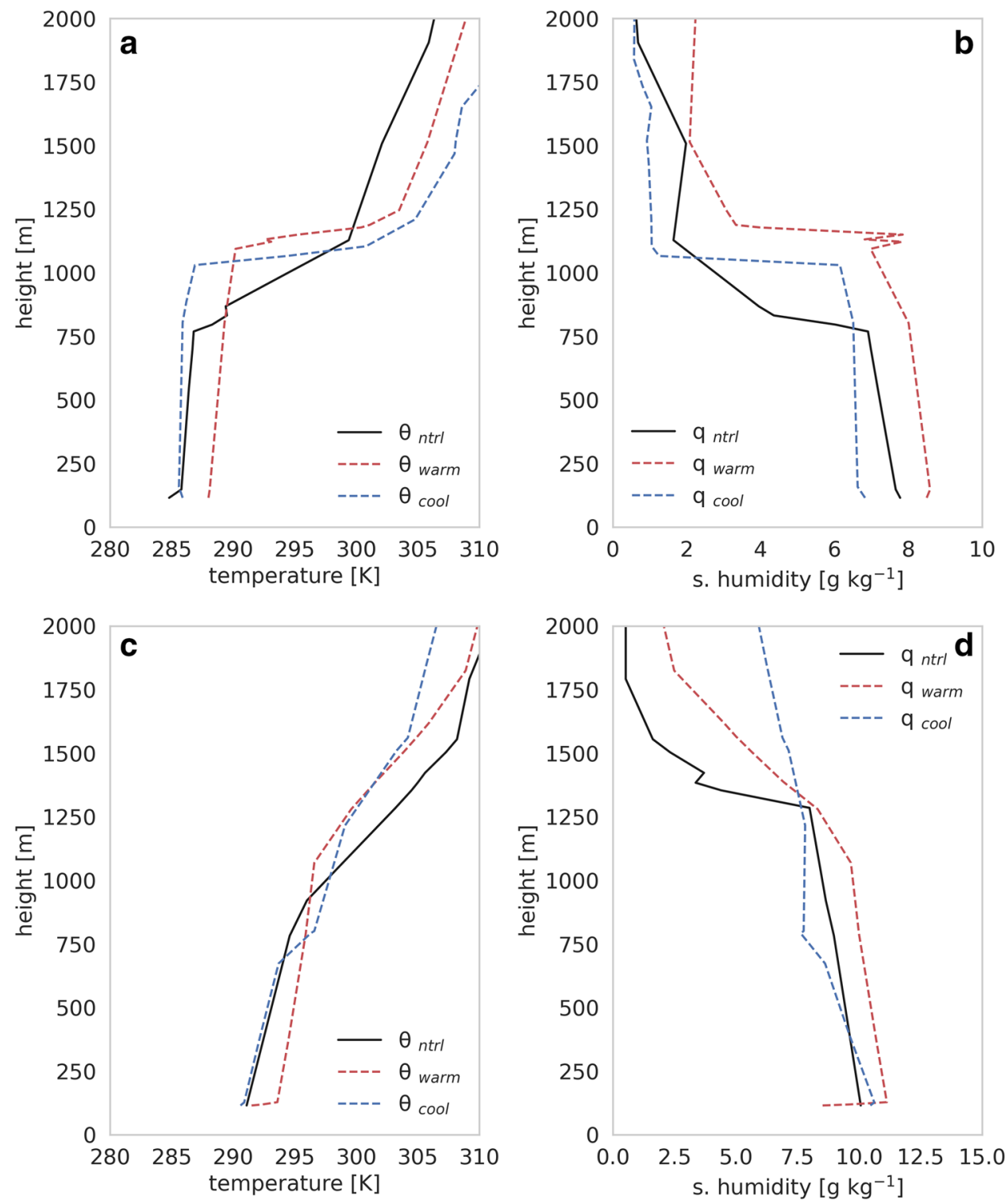

condense. These interpretations agree with previous studies that show a higher advective fog frequency during winter and a higher orographic fog frequency during summer in the study area (Cereceda et al. 2002, 2008).

The FLCs interannual variability reveals the role played by ENSO in the cloud presence over the coastal Atacama Desert. Here, ENSO phases directly affect the interaction among the marine boundary layer, the free troposphere and the sea surface temperature (Schubert et al. 1979). Figure 11 summarizes our interpretation of this phenomenon under four scenarios: (a) cool ENSO phases in September, (b) warm ENSO phases in September, (c) cool ENSO phases in February and (d) warm ENSO phases in February. In September and under a cool ENSO phase, high FLCs arose from the strong advection of the Sc-clouds decks in the study area. These advected clouds remain steady until reaching the coastal cordillera, where cool SSTs contribute to keeping the same ocean conditions. The low surface temperatures also increase the thermal inversion layer, which results in a boundary layer height of around $1000 \mathrm{~m}$. Again in September, but under a warm ENSO phase, the FLCs presence is due to the combination of higher SSTs and a weaker inversion layer, which promotes more entrainment from the dry and free troposphere. This entrainment contributes to dissipating clouds and decreasing the boundary layer height. In February and under a cool ENSO phase, the FLCs presence is related to lower temperature and subsidence than in September. Together with a diminished inversion layer, these conditions provoke higher entrainment and, consequently, a lower boundary layer height. Finally, in February and under a warm ENSO phase, we find a higher FLCs presence compared to a neutral ENSO phase, revealing the role played 

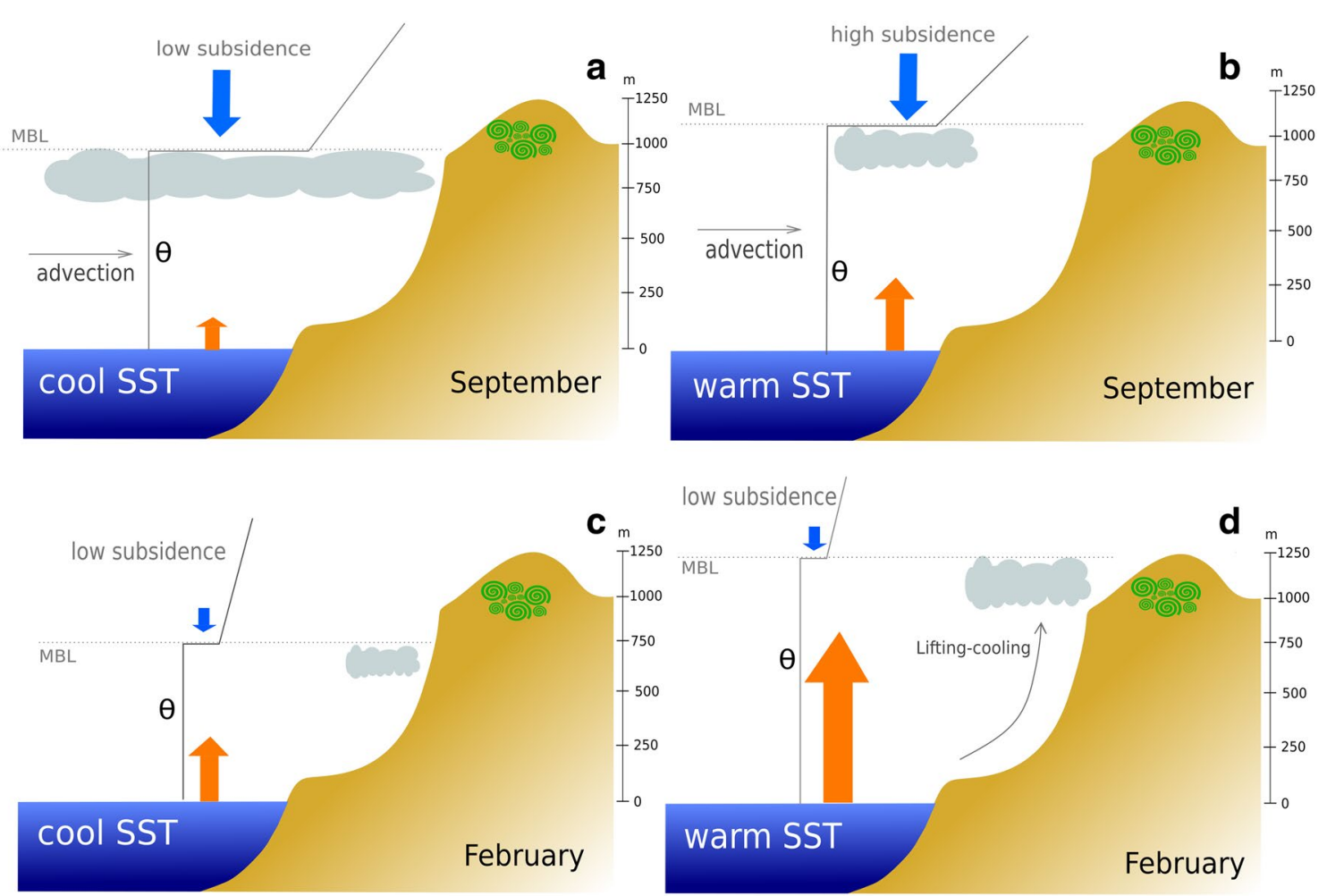

Fig. 11 Schematic FLCs formation under four scenarios: a cool ENSO phases in September, $\mathbf{b}$ warm ENSO phases in September, c cool ENSO phases in February and $\mathbf{d}$ warm ENSO phases in February

by the topography. In this case, the MBL is the warmest and moistest, while higher surface fluxes increase its height. This thicker boundary layer allows warm and moist oceanic air masses to cool while lifting above the coastal cordillera, enhancing their condensation.

\section{Insights into Tillandsia Landbeckii past and present distribution}

The FLCs presence is strongly related to water availability and, therefore, to fog-driven ecosystems such as the Tillandsia landbeckii lomas vegetation. Studies have shown that $T$. landbeckii plants derive from fog not only moisture but also key nutrients such as nitrogen and phosphorus (Gonzalez et al. 2011a; Latorre et al. 2011; Jaeschke et al. 2019). These inputs provide sustenance for an ecological community of consumers (González et al. 2011b). Hence, it stands to reason that the T. landbeckii ecosystems distribution is sensitive to FLCs spatiotemporal variations, acting as a "biosensor" of fog availability. The long-term history of the evolution of this highly specialized species and its actual distribution pattern may hint that, while being adapted to a minimum average fog occurrence during the entire growing season, these species do not tolerate long-term stochasticity and large variation of such fog events. The data reported in Table 1 support this assumption by showing that the area between

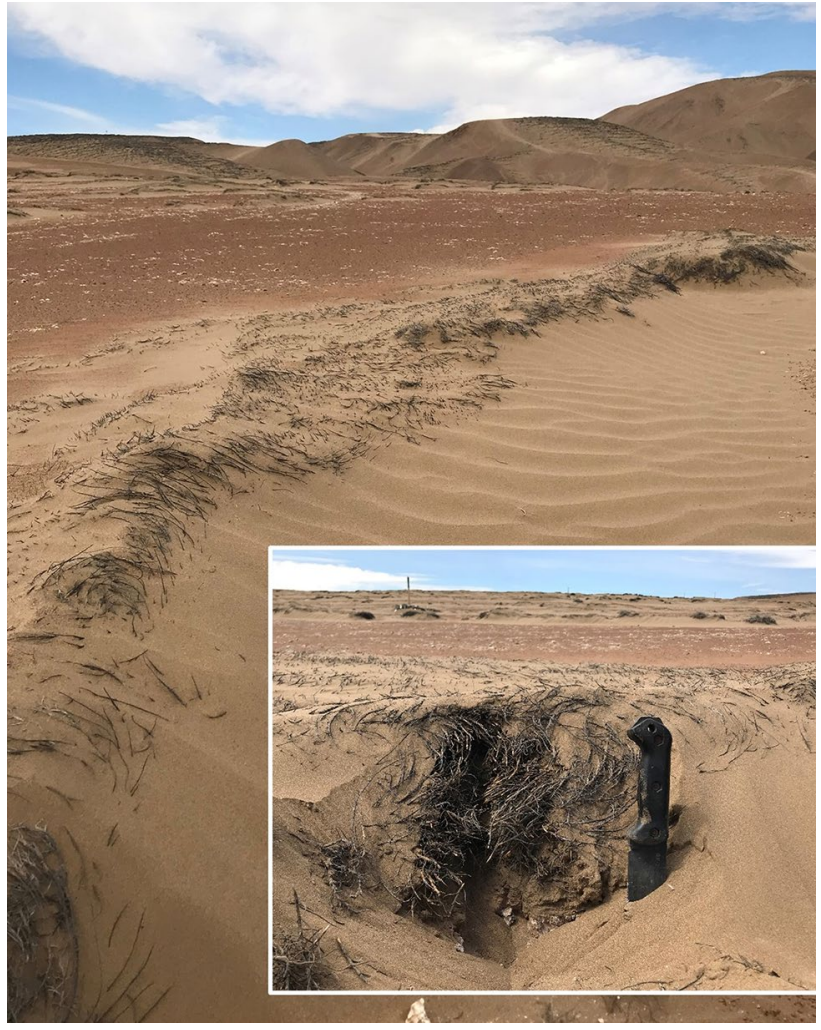

Fig. 12 Dried belts of Tillandsia landbeckii along the lower margins of the Cerro Oyarbide. The knife handle measures $\sim 20 \mathrm{~cm}$ 
15 and $25 \mathrm{~km}$ inland (clusters 2 and 3), which is the Chilean coastal region harboring $T$. landbeckii loma vegetation (e.g., Koch et al. 2020), also presents the lower variation of FLCs occurrence.

According to the previously described results, the weak decreasing (increasing) trend of fog presence at altitudes above (below) the $1000 \mathrm{~m}$ a. s. 1. may have already significantly affected the survival of these ecosystems over the past 2-3 decades. This repercussion may be evident especially along the margins of the Tillandsia distribution, which could be susceptible areas to such changes. For example, the Tillandsia lomas at Cerro Oyarbide recently show significant mortality along the lower margins (approximately between 900 and $1050 \mathrm{~m}$ a. s. 1.) of its distribution (Fig. 12). Moreover, the altitude range of this phenomenon (around the $1000 \mathrm{~m}$ a. s. 1.) appears to be relevant to the atmosphere-biosphere relationship due to the increasing LCL (Lifting Condensation Level) altitude, the downward cloud base altitude trend (Muñoz et al. 2011, 2016), and the resulting variations in exposures to wetter-coastal or drier-desertic conditions (Schween et al. 2020; García et al. 2021). This critical relationship between FLCs distribution and Tillandsia dieback is worth to be further studied. Finally, the radiocarbon analysis of the affected vegetation bands provided information about the time of their death, thus a better understanding of the temporal distribution of these past changes. Indeed, some of these preserved bands date back to several thousand years and are located at elevations where no Tillandsia ecosystems are found today (Latorre et al. 2011). Therefore, the herein presented data of increased stochasticity of the ENSO climate system may explain the large-scale dieback of Tillandsia lomas in the Atacama Desert.

\section{Conclusions}

Through this paper, we explored fog and low clouds (FLCs) variations within the hyper-arid coastal Atacama Desert and the influence of this phenomenon on fog-dependent Tillandsia landbeckii ecosystems. Our study led us to the following conclusions:

- Satellite results concerning FLCs occurrence on the coastal Atacama allowed us to describe and analyze recent changes (1995-2017) in FLCs spatial distribution, interannual variability, trends and its relationship with oceanic indices. During September (winter-early spring), FLCs presence trends are weak-positive over the ocean and onshore areas located below $1000 \mathrm{~m}$ a. s. l. Contrary, those areas close to the coast and above $1000 \mathrm{~m}$ a. s. 1 . present weak-negative FLCs trends, revealing a spatial asymmetry in fog distribution and coverage due to the decreased height of the thermal inversion layer in the recent decades (Muñoz et al. 2016). February (summer) data do not present statistically significant trends.

- ENSO exerts a significant influence on the FLCs interannual variability in the coastal Atacama. More precisely, ENSO phases (El Niño (warm)/La Niña (cool)) can generate opposite seasonal FLCs effects: whereas during summer (winter) ENSO warm phases correspond to increased (decreased) FLCs presence, ENSO cool phases correspond to decreased (increased) FLCs occurrence.

- During February, in the ocean and onshore areas close to the coast, the FLCs occurrence show significant correlations with ONI $(r=+0.66$ and $r=+0.68$, respectively). More specifically, our linear regression analyses revealed that the ONI explains $\sim 50 \%$ of the interannual FLCs variance in the Atacama. During September, the analysis indicates that ENSO anomalies explain $\sim 47$ and $\sim 66 \%$ of the interannual FLCs variance in the oceanic and onshore areas, respectively.

- Analyzing radiosondes observations of the marine boundary layer vertical structure contributes to understanding ENSO influence on the FLCs presence. On the one hand, during winter ENSO cool phases provoke a stronger inversion layer, affecting the fog formation positively. On the other hand, during summer, ENSO warm phases cause a higher inversion layer, which, combined with the coastal topography, affects fog formation positively through lifting and cooling.

- Over its long evolutionary history, Tillandsia landbeckii has adapted to the ENSO climate system. However, changes in ENSO oscillation over the past few decades have negatively affected the current vegetation, and this might be the primary reason for the ongoing dieback affecting this species.

Acknowledgements Camilo del Río would like to thank the ANID/ FONDECYT Initiation grant No.11200789 and the Centro UC Desierto de Atacama for supporting this research. Claudio Latorre thanks the ANID/FONDECYT 1191568 and the ANID CCTE AFB170008 Fabrice Lambert gratefully acknowledges the support of the projects ANID/FONDECYT 1191223, ANID/Fondap 15110009, and Millennium Nucleus Paleoclimate NCN17_079. Additionally, the authors want to thank Daniela Rivera for her valuable image-processing work. We express our gratitude to BMBF, which supported this research through the ERANet-LAC program of the EU to A. S. and M.A.K. Finally, we also thank the two anonymous reviewers for their valuable comments, which contribute to improving the quality of this paper.

Author contribution statement CdR was involved in conceptualization, formal analysis, investigation, writing the manuscript. FL-R helped in formal analysis, investigation, responsible for reviewing the manuscript. CL, MAK, J-LG, PO, FL and FA were involved in investigation, responsible for reviewing the manuscript. AS helped in conceptualization, responsible for reviewing the manuscript. 
Funding Open Access funding enabled and organized by Projekt DEAL. This study is financed by the ANID/FONDECYT grant No. 11200789 of the Ministry of Science, Chile (to Camilo del Río). This study is also supported in the framework of the international ERANetLAC program, project $\mathrm{N}^{\circ}$ ELAC2015/T01-0872, funded by BMBF (Germany) and ANID/PCI (Chile) (To C.dR, C.L, M.A.K, J-L.G, P.O, A.S.)

Code availability Not applicable.

Availability of data and material (data transparency) The datasets generated during and/or analyzed during the current study are available from the corresponding author on reasonable request.

\section{Declarations}

Conflict of interest The authors declare that there is no conflict of interest.

Open Access This article is licensed under a Creative Commons Attribution 4.0 International License, which permits use, sharing, adaptation, distribution and reproduction in any medium or format, as long as you give appropriate credit to the original author(s) and the source, provide a link to the Creative Commons licence, and indicate if changes were made. The images or other third party material in this article are included in the article's Creative Commons licence, unless indicated otherwise in a credit line to the material. If material is not included in the article's Creative Commons licence and your intended use is not permitted by statutory regulation or exceeds the permitted use, you will need to obtain permission directly from the copyright holder. To view a copy of this licence, visit http://creativecommons.org/licenses/by/4.0/.

\section{References}

Amundson R, Dietrich W, Bellugi D, Ewing S, Nishiizumi K, Chong G, Owen J, Finkel R, Heimsath A, Stewart B, Caffee M (2012) Geomorphologic evidence for the late Pliocene onset of hyperaridity in the Atacama Desert. GSA Bulletin 124:1048-1070. https://doi.org/10.1130/B30445.1

Andersen H, Cermak J (2018) First fully diurnal fog and low cloud satellite detection reveals life cycle in the Namib. Atmos Meas Techn 11:5461-5470. https://doi.org/10.5194/amt-11-5461-2018

Anthis A, Cracknell AP (1999) Use of satellite images for fog detection (AVHRR) and forecast of fog dissipation (METEOSAT) over lowland Thessalia, Hellas. Int J Remote Sensing 20:1107-1124. https://doi.org/10.1080/014311699212876

Armijo R, Lacassin R, Coudurier-Curveur A, Carrizo D (2015) Coupled tectonic evolution of Andean orogeny and global climate. Earth Sci Rev 143:1-35. https://doi.org/10.1016/j.earscirev.2015. 01.005

Bendix J (2002) A satellite-based climatology of fog and low level stratus in Germany and adjacent areas. Atmos Res 64:3-18. https:// doi.org/10.1016/S0169-8095(02)00075-3

Borthagaray AI, Miguel A, Fuentes MA, Marquet PA (2010) Vegetation pattern formation in a fog-dependent ecosystem. $\mathrm{J}$ Theor Biol 265:18-26. https://doi.org/10.1016/j.jtbi.2010.04.020

Cereceda P, Osses P, Larrain H, Farías M, Pinto R, Schemenauer RS (2002) Advective, orographic and radiation fog in the Tarapacá region, Chile. Atmos Res 64:261-271. https://doi.org/10.1016/ S0169-8095(02)00097-2

Cereceda P, Larraín H, Osses P, Farías M, Egaña I (2008) The spatial and temporal variability of fog and its relation to fog oases in the
Atacama Desert, Chile. Atmos Res 87:312-323. https://doi.org/ 10.1016/j.atmosres.2007.11.012

Cermak J (2012) Low clouds and fog along the south-western African coast - satellite-based retrieval and spatial patterns. Atmos Res 116:15-21. https://doi.org/10.1016/j.atmosres.2011.02.012

Clarke J (2006) Antiquity of aridity in the Chilean Atacama Desert. Geomorphology 73:101-114. https://doi.org/10.1016/j.geomorph. 2005.06.008

del Río C (2020) Spatiotemporal characteristics of coastal fog in the Atacama Desert. A remote sensing based analysis of the past, present and future distribution and variability of low clouds under climate change in a hyper-arid region of northern Chile. Heidelberg University Library, Heidelberg

del Río C, Garcia J-L, Osses P, Zanetta N, Lambert F, Rivera D, Siegmund A, Wolf N, Cereceda P, Larraín H, Lobos F (2018) ENSO influence on coastal fog-water yield in the Atacama Desert, Chile. Aerosol Air Qual Res 18:127-144. https://doi.org/10.4209/aaqr. 2017.01.0022

del Río C, Lobos F, Siegmund A, Tejos C, Osses P, Huaman Z, Meneses JP, García JL (2021) GOFOS, Ground Optical Fog Observation System for monitoring the vertical stratocumulus-fog cloud dynamic in the coast of the Atacama Desert, Chile. J Hydrol 597:126190. https://doi.org/10.1016/j.jhydrol.2021.126190

Ellrod G (1995) Advances in the detection and analysis of Fog at night using GOES multispectral infrared imagery. Weath Forecast 10:606-619. https://doi.org/10.1175/1520-0434(1995)010\% 3c0606:AITDAA\%3e2.0.CO;2

Eyre JR (1984) Detection of fog at night using Advanced Resolution Radiometer (AVHRR) imagery. Meteorol Mag 113:266-271

Falvey M, Garreaud R (2009) Regional cooling in a warming world: Recent temperature trends in the SE Pacific and along the west coast of subtropical South America (1979-2006). J Geophys Res 114:D04102. https://doi.org/10.1029/2008JD010519

Farías M, Cereceda P, Osses P, Larraín H (2005) Comportamiento espacio temporal de la nube estratocúmulo, productora de niebla en la costa del desierto de Atacama ( $21^{\circ}$ lat. S., $70^{\circ}$ long W.) durante un mes de invierno y otro de verano. Invest Geog $56: 43-61$

García J-L, Lobos-Roco F, Schween JH, del Río C, Osses P, Vives R, Pezoa M, Siegmund A, Latorre C, Alfaro F, Koch MA, Loehnert U (2021) Climate and coastal low-cloud dynamic in the hyperarid Atacama fog Desert and the geographic distribution of Tillandsia landbeckii (Bromeliaceae) dune ecosystems. Pl Syst Evol 307(accepted)

Garreaud R, Barichivich J, Christie D, Maldonado A (2008) Interannual variability of the coastal fog at Fray Jorge relicts forests in semiarid Chile. J Geophys Res 113:G04011. https://doi.org/10. 1029/2008JG000709

Garreaud RD, Rutllant JA, Muñoz RC, Rahn DA, Ramos M, Figueroa D (2011) VOCALS-CUpEx: the Chilean upwelling experiment. Atmos Chem Phys 11:2015-2029. https://doi.org/10.5194/ acp-11-2015-2011

Garreaud R, Christie D, Barichivih J, Maldonado A (2007) Climate, Weather and Fog along the west coast of Subtropical South America. In: 4th International Conference on Fog, Fog Collection and Dew, Proceedings, La Serena, Chile, 2007, pp 22-27

Gayo EM, Latorre C, Jordan TE, Nester PL, Estay SA, Ojeda KF, Santoro CM (2012) Late Quaternary hydrological and ecological changes in the hyperarid core of the northern Atacama Desert ( 21 $\left.{ }^{\circ} \mathrm{S}\right)$. Earth Sci Rev 113:120-140. https://doi.org/10.1016/j. earscirev.2012.04.003

González AL, Fariña JM, Pinto R, Pérez C, Weathers KC, Armesto JJ, Marquet PA (2011a) Bromeliad growth and stoichiometry: responses to atmospheric nutrient supply in fog-dependent ecosystems of the hyper-arid Atacama Desert, Chile. Oecologia 167:835-845. https://doi.org/10.1007/s00442-011-2032-y 
González AL, Fariña JM, Kay AD, Pinto R, Marquet PA (2011b) Exploring patterns and mechanisms of interspecific and intraspecific variation in body elemental composition of desert consumers. Oikos 120(8):1247-1255. https://doi.org/10.1111/j.1600-0706. 2010.19151.x

Gorelick N, Hancher M, Dixon M, Ilyushchenko S, Thau D, Moore R (2017) Google Earth Engine: Planetary-scale geospatial analysis for everyone. Remote Sensing Environm 202:18-27. https://doi. org/10.1016/j.rse.2017.06.031

Hartley AJ, Chong G, Houston J, Mather AE (2005) 150 million years of climatic stability: evidence from the Atacama Desert, northern Chile. J Geol Soc 162:421-424. https://doi.org/10.1144/ 0016-764904-071

Henley BJ, Gergis J, Karoly DJ, Power SB, Kennedy J, Folland CK (2015) A Tripole Index for the Interdecadal Pacific Oscillation. Clim Dynam 45:3077-3090. https://doi.org/10.1007/ s00382-015-2525-1

Hesse R (2012) Spatial distribution of and topographic controls on Tillandsia fog vegetation in coastal southern Peru: remote sensing and modelling. J Arid Environm 78:33-40. https://doi.org/10. 1016/j.jaridenv.2011.11.006

Houston J (2006) Variability of precipitation in the Atacama Desert: its causes and hydrological impact. Int J Climatol 26:2181-2198. https://doi.org/10.1002/joc.1359

Jaeschke A, Böhm C, Merklinger FF, Bernasconi SM, Reyers M, Kusch S, Rethemeyer J (2019) Variation in $\delta 15 \mathrm{~N}$ of fog-dependent Tillandsia ecosystems reflect water availability across climate gradients in the hyperarid Atacama Desert. Global Planet Change 183:103029. https://doi.org/10.1016/j.gloplacha.2019.103029.

Jedlovec GJ, Laws K (2003) GOES cloud detection at the Global Hydrology and Climate Center. Paper P1 presented at 12th conference on satellite meteorology and oceanography. American Meteorological Society, Long Beach

Jensen JR (2005) Introductory digital image processing. Pearson Prentice Hall, Upper Saddle River.

Jordan TE, Kirk-Lawlor NE, Blanco N, Rech JA, Cosentino N (2014) Landscape modification in response to repeated onset of hyperarid paleoclimate states since $14 \mathrm{Ma}$, Atacama Desert. Chile Geol Soc Amer Bull 126:1016-1046. https://doi.org/10.1130/B30978.1

Koch MA, Kleinpeter D, Auer E, Siegmund A, del Río C, Osses P, García JL, Marzol MV, Zizka G, Kiefer C (2019) Living at the dry limits. Ecological genetics of Tillandsia lomas in the Chilean Atacama Desert. Pl Syst Evol 305:1041-1053. https://doi.org/10. 1007/s00606-019-01623-0

Koch MA, Stock C, Kleinpeter D, del Río C, Osses P, Merklinger FF, Quandt D, Siegmund A (2020) Vegetation growth and landscape genetics of Tillandsia lomas at their dry limits in the Atacama Desert show fine-scale response to environmental parameters. Ecol Evol 10:13260-13274. https://doi.org/10.1002/ece3.6924

Larraín H, Velásquez F, Cereceda P, Espejo R, Pinto R, Osses P, Schemenauer RS (2002) Fog measurements at the site "Falda Verde" north of Chañaral compared with other fog stations of Chile. Atmos Res 64:273-284. https://doi.org/10.1016/S01698095(02)00098-4

Latorre C, González AL, Quade J, Fariña JM, Pinto R, Marquet PA (2011) Establishment and formation of fog-dependent Tillandsia landbeckii dunes in the Atacama Desert: Evidence from radiocarbon and stable isotopes. J Geophys Res 116:G03033. https://doi. org/10.1029/2010JG001521

Latorre C, Santoro C, Ugalde P, Gayo E, Osorio S-EC, De Pol-Holz R, Joly D, Rech JA (2013) Late Pleistocene human occupation of the hyperarid core in the Atacama Desert, northern Chile. Quatern Sci Rev 77:19-30. https://doi.org/10.1016/j.quascirev.2013.06.008

Lee T, Turk J, Richardson K (1997) Stratus and fog products using GOES-8-9 3.9 $\mu \mathrm{m}$ Data. Weath Forecast 12:664-677. https://doi.
org/10.1175/1520-0434(1997)012\%3c0664:SAFPUG\%3e2.0. $\mathrm{CO} ; 2$

Lobos F, Vilà-Guerau J, Pedruzo-Bagazgoitia X (2018) Characterizing the influence of the marine stratocumulus cloud on the land fog at the Atacama Desert. Atmos Res 214:109-120. https://doi.org/ 10.1016/j.atmosres.2018.07.009

Lobos-Roco F, Hartogensis O, Vilà-Guerau de Arellano J, de la Fuente A, Muñoz R, Rutllant J, Suárez F (2021) Local evaporation controlled by regional atmospheric circulation in the Altiplano of the Atacama Desert. Atmos Chem Phys 21:2021. https://doi.org/10. 5194/acp-21-9125-2021

Manrique R, Ferrari C, Pezzi G (2010) The influence of El Niño Southern Oscillation (ENSO) on fog oases along the Peruvian and Chilean coastal deserts. In: 5th International Conference of Fog and Fog Collection Proc., Munster, pp 148-150.

Masuzawa T (1985) Structure of Tillandsia Lomas Community in Peru. In: Grant-in-aid for Scientific Research Reports for Overseas Scientific Survey. Tokyo Metropolitan University, Tokyo, p 93

McRostie V, Gayo EM, Santoro CM, De Pol-Holz R, Latorre C (2017) The pre-Columbian introduction and dispersal of Algarrobo (Prosopis, Section Algarobia) in the Atacama Desert of northern Chile. PLoS ONE 12:1-15. https://doi.org/10.1371/journal.pone.01817 59

Meehl GA, Teng H, Capotondi A, Hu A (2021) The role of interannual ENSO events in decadal timescale transitions of the Interdecadal Pacific Oscillation. Clim Dynam. https://doi.org/10.1007/ s00382-021-05784-y

Muñoz R, Garreaud R (2005) Dynamics of the Low-Level Jet off the West Coast of Subtropical South America. Monthly Weath Rev 133:3661-3677. https://doi.org/10.1175/MWR3074.1

Muñoz R, Zamora R, Rutllant J (2011) The coastal boundary layer at the eastern Margin of the southeast Pacific (23.4 degrees S, 70.4 degrees W): Cloudiness-conditioned climatology. J Clim 24:1013-1033. https://doi.org/10.1175/2010JCLI3714.1

Muñoz R, Quintana J, Falvey M, Rutllant J, Garreaud R (2016) Coastal clouds at the eastern Margin of the southeast Pacific: Climatology and trends. J Clim 29:4525-4542. https://doi.org/ 10.1175/JCLI-D-15-0757.1

Muñoz-Schick M, Pinto R, Mesa A (2001) Oasis de neblina en los cerros costeros del sur de Iquique, región de Tarapacá, Chile, durante el evento El Niño 1997-1998. Revista Chilena Hist Nat 74:389-405. https://doi.org/10.4067/S0716-078X20010002000 14

Ortlieb L (1995) Eventos El Niño y episodios lluviosos en el desierto de Atacama: el registro de los últimos dos siglos. Bull Inst Franç Études Andines 24:191-212

Pfeiffer M, Latorre C, Santoro CM, Gayo EM, Rojas R, Carrevedo ML, McRostie VB, Finstad KM, Heimsath A, Jungers MC, De Pol-Holz R, Amundson R (2018) Chronology, stratigraphy and hydrological modelling of extensive wetlands and paleolakes in the hyperarid core of the Atacama Desert during the late quaternary. Quatern Sci Rev 197:224-245. https://doi.org/10.1016/j. quascirev.2018.08.001

Pinto R, Barria I, Marquet PA (2006) Geographical distribution of Tillandsia lomas in the Atacama Desert, northern Chile. J Arid Environm 65:543-552. https://doi.org/10.1016/j.jaridenv.2005. 08.015

Power S, Casey T, Folland C, Colman A, Mehta V (1999) Inter-decadal modulation of the impact of ENSO on Australia. Clim Dynam 15:319-324. https://doi.org/10.1007/s003820050284

Quintana J, Berríos P (2007) Study of the coastal low cloud in the northern coast of Chile: Variability and tendency. In: Proceedings of Fourth International Conference on Fog, Fog Collection and Dew, La Serena, Chile, FogQuest, pp 189-192 
Rundel PW, Dillon MO (1998) Ecological patterns in the Bromeliaceae of the lomas formation of Coastal Chile and Peru. Pl Syst Evol 212:261-278. https://doi.org/10.1007/BF01089742

Rutllant J, Fuenzalida H, Aceituno P (2003) Climate dynamics along the arid northern coast of Chile: the 1997-1998 Dinámica del Clima de la Región de Antofagasta (DICLIMA) experiment. J Geophys Res 108:4538. https://doi.org/10.1029/2002JD003357

Santoro CM, Capriles JM, Gayo EM, de Porras ME, Maldonado A, Standen VG, Latorre C, Castro V, Angelo D, McRostie V, Uribe M, Valenzuela D, Ugalde PC, Marquet PA (2017) Continuities and discontinuities in the socio-environmental systems of the Atacama Desert during the last 13,000 years. J Anthropol Archaeol 46:28-39. https://doi.org/10.1016/j.jaa.2016.08.006

Schemenauer RS, Cereceda P (1994) A proposed standard fog collector for use in high elevation regions. J Appl Meteorol 33(11):11131322. https://doi.org/10.1175/1520-0450(1994)033\%3c1313: APSFCF\%3e2.0.CO;2

Schubert WH, Wakefield JS, Steiner EJ, Cox SK (1979) Marine stratocumulus convection. Part II: Horizontally inhomogeneous solutions. J Atmos Sci 36:1308-1324. https://doi.org/10.1175/15200469(1979)036<1308:MSCPIH>2.0.CO;2

Schulz N, Boisier JP, Aceituno P (2011a) Climate change along the arid coast of northern Chile. J Clim 32:1803-1814. https://doi. org/10.1002/joc. 2395

Schulz N, Aceituno P, Richter M (2011b) Phytogeographic divisions, climate change and plant dieback along the coastal desert of northern Chile. Erdkunde 65:169-197. https://doi.org/10.3112/erdku nde.2011.02.05

Schween JH, Hoffmeister D, Loehnert U (2020) Filling the observational gap in the 921 Atacama Desert with a new network of climate stations. Global Planet Change 184:103034. https://doi.org/ 10.1016/j.gloplacha.2019.103034

Seethala C, Norris JR, Myers TA (2015) How has subtropical stratocumulus and associated meteorology changed since the 1980s? J Clim 28:8396-8410. https://doi.org/10.1175/JCLI-D-15-0120.1

Serpetzoglou E, Albrecht BA, Kollias P, Fairall C (2008) Boundary layer, cloud, and drizzle variability in the southeast Pacific stratocumulus regime. J Clim 21:6191-6214. https://doi.org/10.1175/ 2008JCLI2186.1

Sohn BJ, Yeh SW, Schmetz J, Song HJ (2013) Observational evidences of Walker circulation change over the last 30 years contrasting with GCM results. Clim Dynam 40:1721-1732. https://doi.org/ 10.1007/s00382-012-1484-Z

Thiel M, Macaya E, Acuña E, Arntz W, Bastias H, Brokordt K, Camus P, Castilla JC, Castro L, Cortés M, Dumont CP, Escribano R,
Fernández M, Gajardo JA, Gaymer C, Gómez I, González AE, González H, Haye PA, Illanes J, Iriarte J, Lancellotti D, LunaJorquera G, Carolina Luxoro PH, Manríquez V, Marín P, Muñoz S, Navarrete E, Pérez E, Poulin J, Sellanes H, Sepúlveda W, Stotz F, Tala A, Thomas C, Vargas JA, Vásquez JA, Vega (2007) The Humboldt current system of northern and central Chile: Oceanographic processes, ecological interactions and socioeconomic feedback. Oceanogr Mar Biol 45:195-344. https://doi.org/10. 1201/9781420050943.ch6

Torregrosa A, Combs C, Peters J (2015) GOES-derived fog and low cloud indices for coastal north and central California ecological analyses. Earth Space Sci 3:46-67. https://doi.org/10.1002/2015E A000119

Underwood J, Ellrod G, Kuhnert A (2004) A multiple-case analysis of nocturnal radiation-fog development in the central valley of California utilizing the GOES nighttime fog product. J Appl Meteorol 43:297-311. https://doi.org/10.1175/1520-0450(2004)043\% 3c0297:AMAONR\%3e2.0.CO;2

Vargas C (2019) Relación espaciotemporal entre temperatura superficial del mar (TSM) y presencia de niebla, en la costa de la región de Tarapacá. Pontificia Universidad Católica de Chile Library, Chile

Vuille M, Franquist E, Garreaud R, Lavado W, Bolivar Cáceres C (2015) Impact of the global warming hiatus on Andean temperature. J Geophys Res 120:3745-3757. https://doi.org/10.1002/ 2015JD023126

Witiw MR, LaDochy S (2015) Cool PDO phase leads to recent rebound in coastal southern California fog. DIE ERDE 146:232-244. https://doi.org/10.12854/erde-146-18

Wood R (2012) Stratocumulus clouds. Monthly Weath Rev 140(8):2373-2423

Wood R, Mechoso CR, Bretherton CS, Weller RA, Huebert BJ et al (2011) The VAMOS OceanCloud-Atmosphere-Land Study Regional Experiment (VOCALS-REx): goals, platforms, and field operations. Atmos Chem Phys Euro Geosci Union 11:627-654. https://doi.org/10.5194/acp-11-627-2011

Publisher's Note Springer Nature remains neutral with regard to jurisdictional claims in published maps and institutional affiliations. 